\title{
Computation of full-field displacements in a scaffold implant using Digital Volume Correlation and Finite Element Analysis
}

\author{
K. Madi*1, G. Tozzi* , Q.H. Zhang*, J. Tong* , A. Cossey*** , A. Au***, D. Hollis ${ }^{+}$and F. Hild ${ }^{++}$ \\ * Mechanical Behaviour of Materials Laboratory, University of Portsmouth, UK \\ **Queen Alexandra Hospital, Cosham, UK \\ ***Smith \& Nephew Inc., Advanced Surgical Devices Divisions, Andover, MA, USA \\ ${ }^{+}$LaVisionUK Ltd, Grove Technology Park Grove, Oxon, UK \\ ${ }^{++}$LMT Cachan, ENS Cachan/CNRS/UPMC/PRES UniverSud Paris, Cachan, France
}

\begin{abstract}
Measurements of three-dimensional displacements in a scaffold implant under uniaxial compression have been obtained by two Digital Volume Correlation (DVC) methods, and compared with those obtained from micro-finite element models. The DVC methods were based on two approaches, a local approach which registers independent small volumes and yields discontinuous displacement fields; and a global approach where the registration is performed on the whole volume of interest, leading to continuous displacement fields. A customised mini-compression device was used to perform in situ step-wise compression of the scaffold within a micro-computed tomography $(\mu \mathrm{CT})$ chamber, and the data were collected at steps of interest. Displacement uncertainties, ranging from 0.006 to 0.02 voxel (i.e.0.12 to $0.4 \mu \mathrm{m}$ ), with a strain uncertainty between 60 and $600 \mu \varepsilon$, were obtained with a spatial resolution of 32 voxels using both approaches, although the global approach has lower systematic errors. Reduced displacement and strain uncertainties may be obtained using the global approach by increasing the element size; and using the local approach by increasing the number of intermediary sub-volumes. Good agreements between the results from the DVC measurements and the FE simulations were obtained in the primary loading direction as well as in the lateral directions. This study demonstrates that volumetric strain measurements can be obtained successfully using DVC, which may be a useful tool to investigate mechanical behaviour of porous implants.
\end{abstract}

Keywords: micro-computed tomography, cellular material, digital volume correlation, local approach, global approach, finite element analyses, measurement uncertainties

\footnotetext{
${ }^{1}$ Corresponding author: Tel: +44-(0)239284 2393; fax: +44-(0)239284 2351.

Email address: kamel.madi@port.ac.uk (K. Madi)
} 


\section{Introduction}

Studies on the relationships between the morphology and the mechanical behaviour of biological tissues and biomaterials are critical to biomedical engineering applications of joint repair and replacement materials. With the recent and rapid progress of micro-focus computed tomography $(\mu \mathrm{CT})$ combined with the development of in situ experiments [1-3], Digital Volume Correlation (DVC) has become a powerful tool to capture 3D strain distributions in solid and cellular materials [4-12].

Two approaches to image correlation have been mainly used for quantifying continuum-level strain measurements. The first approach, the most commonly used, is a local analysis, which consists of dividing the reference and the deformed images into smaller interrogation windows that are then individually correlated. It was developed and first applied in solid mechanics at the beginning of the 1980 's, in $2 \mathrm{D}[13,14]$, then applied to a variety of methods $[15,16]$ and extended to 3D surface $[17,18]$ and volume measurements $[4,19,20]$. Since then, several robust and accurate DVC algorithms have been developed, based mainly on cross-correlation and sum of squared differences criteria, with displacement uncertainties ranging between $10^{-2}$ voxel $[6,21-23]$ and $10^{-1}$ voxel $[4,7,9,12,19,24,25]$. The second approach, referred to as global, estimates the displacement fields from pairs of images based on a continuous and global field, as commonly used in finite element simulations. Developed first in 2D [26-28], this approach has been extended to 3D [11] and applied with success to solid and cellular materials $[5,10,11]$. Although improvements have been made for both local and global approaches to DVC, a systematic comparison of the two methods in terms of performance and local strain fields has yet to emerge, especially for materials with foam-like morphologies $[5,9,11]$. In 2D, the global approach has been shown to be more accurate in solid materials when compared to FFT-based or other local algorithms $[28,29]$, but such comparison in 3D has never been tested in either solid or cellular materials. Since the local and global approaches to DVC are close in spirit to the two-dimensional case, it is hypothesized that the global approach may also outperform the FFT-based local approach. 
Micro-finite element (micro-FE) models generated from high resolution micro-CT images (up to $\sim 10 \mu \mathrm{m}$ resolution) have proven to be a powerful tool to simulate the mechanical behaviour of cellular materials such as polymeric foams [30,31], metallic foams [32,33], scaffolds [34,35] and more extensively trabecular bone [36-41]. Despite the significant modelling progress, the accuracy of this approach in predicting the material constitutive behaviour could still be improved. Amongst the limitations that have been extensively discussed in the previous studies [37-41], the boundary conditions are cited as a possible source of errors. Comparing finite element predictions with DVC measurements was attempted for cancellous bone to validate the strain predictions of the FE model [21]. A good agreement was obtained in the loading direction, yet less accuracy was achieved in the transverse directions. It is hypothesised that parameters affecting the accuracy may include lateral and vertical boundary conditions.

The above hypotheses are tested by first measuring the uncertainty levels and analysing the local strain fields of a polymer foam implant in a FFT-based local approach and a global approach to DVC. Secondly, the results from the two DVC approaches are compared with those obtained from the FE model, the latter being developed from the same $\mu \mathrm{CT}$ data sets as used in DVC. The experimental displacements obtained by the two DVC methods are applied as boundary conditions on the external faces of the FE model.

\section{Methods}

\subsection{Experimental methods}

\subsubsection{Material and specimen}

A scaffold implant material (Smith \& Nephew) was used for this study. The scaffold material was taken from a dual-layer cylindrical implant that mimics cartilage and bone for knee repair purposes [42] and made of 85:15 Poly(D,L-lactide-co-glycolide). Only the bone layer was retained, with a diameter of $8.57 \mathrm{~mm}$ and a height of $14.7 \mathrm{~mm}$. 


\subsubsection{Micro-compression device}

A novel customised micro-mechanical loading device (Deben Ltd, UK), equipped with a 3kN miniature load cell, was used to load the sample in the micro-CT chamber (Nikon XTH-225 X-Ray \& CT Inspection System, see Fig. 1a). This loading device, as shown in Fig. 1b, has been used in previous studies [43]. It has a torque accurately applied by a DC motor, which is then transmitted to a ballscrew system via a set of gears, resulting in the application of precise strain steps without introducing fluctuation errors. The nominal torque is $23 \mathrm{mNm}$ and calculated to provide a required nominal axial force of about $70 \mathrm{~N}$. The system drives the jaws symmetrically in opposite directions, with screws S1 and S3 driving the complex carbon fibre tube-actuator from the top and S2 driving the sample from the bottom simultaneously. The loading stage employs an analogue resistive extensometer with a 16-bit AD converter for accurate elongation measurement, achieving a nominal strain resolution of around $15 \mu \varepsilon$. Using the same converter, a typical resolution range of 1000:1 (dynamic) to 2000:1 (static) may be achieved for the load cell (i.e. 3N resolution for a $3 \mathrm{kN}$ load cell), with an overall uncertainty of $+/-1 \%$ of full scale. The motor is linked to a board card and to the extensometer using a closed-loop system for accurate position and speed control via the Deben Microtest software (Microtest, Deben Ltd, East Grinstead, UK), where data acquisition in the form of force-extension curves are displayed and recorded.

\subsubsection{In situ testing and time-lapsed imaging}

Before testing, the sample was glued on the lower compressive platen of the stage and a preload of $5 \mathrm{~N}$ was applied at the top platen. A complete scan was performed at the preloaded state prior to testing (Fig.2). The scanner settings were set to a voltage of $60 \mathrm{kV}$, current of $51 \mu \mathrm{A}$ and an isotropic voxel size of $20 \mu \mathrm{m}$. The specimen was then step-wise compressed to -0.441 and $-0.879 \mathrm{~mm}$ displacements (i.e. $-3 \%$ and $-6 \%$ strains) at a constant displacement rate of $0.01 \mathrm{~mm} / \mathrm{s}$. Following the application of each displacement step, the specimen was allowed to relax for $15 \mathrm{~min}$, due to its viscoelastic properties, before the micro-CT acquisition procedure was repeated. Approximately one hour scan time was required for scanning and additional 10-min time for reconstruction from 1500 
angular projections using CT-Pro XT software (XT Software suite, 2.2, Nikon Metrology Ltd, Derby, UK).

\subsection{Displacement measurement by Digital Volume Correlation (DVC)}

Two DVC methods were used to compute the 3D displacement and strain fields from the same pair of images, namely, the reference reconstructed image obtained in the preloaded stage and the deformed image obtained after compressing the specimen to $-3 \%$ strain along (Oz) direction (Fig.2). Figure 3 shows the differences between the local and the global approaches used herein. The spatial resolution is defined as the length scale of the displacement and strain measurements, i.e. the size of the correlation window (local approach) or twice the element size (global approach).

\subsubsection{Local correlation algorithm}

The local correlation algorithm (LA-DVC), implemented into the LaVision DVC software (Davis, 8.0.1, LaVision $\mathrm{GmbH}$, Goettingen, Germany), uses fast Fourier transform (FFT) cross-correlation to compare sub-volumes (Fig. 3a), and a multi-pass approach that uses the displacement gradient information from the previous passes to deform the sub-volumes on the subsequent passes [44]. In the present case, final sub-volumes of $32 \times 32 \times 32$ voxels $^{3}$ overlapped by $50 \%$ were reached after successive passes using sub-volumes of $96 \times 96 \times 96$ voxels $^{3}$ and $64 \times 64 \times 64$ voxels $^{3}$. From the displacements at the centre of the sub-volumes, all the components of the Green-Lagrange strain tensor were calculated using a centred finite differences scheme [24].

\subsubsection{Global correlation algorithm}

The second correlation code (Correli-C8, 1.2, LMT-Cachan, Cachan, France) is based on a continuous and global approach to DVC $[5,11]$ and will be designated by GA-DVC. The whole volume of interest is analysed and the sum of squared differences is minimized with respect to the unknown kinematic degrees of freedom by resorting to a multiscale procedure (Fig. 3b). In the present case, a Galerkin approach based upon 8-nodebrick (C8) elements is chosen. A trilinear displacement interpolation is used, and a spline grey level interpolation. When the correlation procedure has converged, its 
quality is evaluated using the dimensionless correlation residuals (Equation (2)), $r_{G A-D V C}$, that are computed as the absolute difference between the reference volume, and the deformed one corrected by the measured displacement field. The only parameter to be chosen by the user is the element edge size. For comparison purposes, an element size of 32 voxels was selected and the mean Green-Lagrange strains per element were computed.

\subsubsection{Performance evaluation}

Successive sub-voxel displacements over a range of one voxel were artificially prescribed in each direction by using the shift / modulation property of FFTs, thereby creating new 'deformed' volumes. These artificial volumes were then correlated with the original one using final sub-volumes of $32 \times 32 \times 32$ voxels $^{3}$ and $64 \times 64 \times 64$ voxels $^{3}$ for the local approach. Final sub-volumes of $32 \times 32 \times 32$ voxels $^{3}$ overlapped by $50 \%$ were reached following the procedure described in Section 2.2.1. Final sub-volumes of $64 \times 64 \times 64$ voxels $^{3}$ overlapped by $50 \%$ were reached after passes using sub-volumes of $96 \times 96 \times 96$ voxels $^{3}$.

Since the global approach is based on finite elements, the evaluation of any degree of freedom of an interior node uses the 8 elements with which it is connected. Therefore the spatial resolution of the global approach is twice the element size. For comparison purposes, volumes with element sizes of $16 \times 16 \times 16$ voxels ${ }^{3}$ and $32 \times 32 \times 32$ voxels ${ }^{3}$ are analysed

The errors in the vertical and lateral displacements $\left(\mathrm{u}_{x}, \mathrm{u}_{\mathrm{y}}\right.$ and $\mathrm{u}_{\mathrm{z}}$ ) (resp. normal strains, $\varepsilon_{x x}, \varepsilon_{y y}$ and $\varepsilon_{z z}$ ) were estimated from the systematic error (or bias) and the corresponding standard deviation (or standard uncertainty). The systematic error was calculated only from the difference between the spatial average of the measured displacement and the prescribed translation. The systematic error of the strain was not considered due to exact zero strain predicted by the two correlation methods. The standard displacement and strain uncertainties $\left(\sigma_{u}, \sigma_{\varepsilon}\right)$ were measured from the standard deviation of the displacement and strain fields respectively, relative to their mean values. 


\subsubsection{Reliability and accuracy of the displacement measurements}

The reliability of the displacement measurements was assessed in terms of the quality of the correlation scheme for both DVC methods. For LA-DVC, a normalised cross-correlation coefficient, $r_{L A-D V C}$, based on grey level gaps is used:

$$
r_{L A-D V C}=\frac{\sum_{\underline{X} \in V O I} f(\underline{X}) g\left(\underline{X}^{*}\right)}{\sqrt{\sum_{\underline{X} \in V O I} f(\underline{X})^{2} \sum_{\underline{X}^{*} \in V O I} g\left(\underline{X}^{*}\right)^{2}}}
$$

where, $X$ and $X^{*}$ refer to coordinates (in voxels) of the same material point in the reference and the deformed state; $f$ and $g$ are, respectively, the grey levels of the initial and deformed volumes. A correlation coefficient value, $r_{L A-D V C}$, close to 1 indicates a perfect match. For GA-DVC, a dimensionless correlation residual, $r_{G A-D V C}$, between the two volumes $f$ and $g$ is used:

$$
r_{G A-D V C}=\frac{<\left|g\left(\underline{X}^{*}\right)-f(\underline{X})\right|>}{\max (f(\underline{X}))-\min (f(\underline{X}))}
$$

where $<_{.}>$is the average value over the volume of interest (VOI), $\max ($.$) and \min ($.$) are the$ maximum and minimum values of the grey levels present in the VOI. This indicator is equal to 0 when the two images are identical or when no correlation error occurs.

Prior to the analysis, the accuracy of the reported strain measurements was validated by measuring the Young's modulus of nodular cast iron material using both DVC methods. Five tomographic scans were acquired from a tensile test along the longitudinal axis [45], where the applied load was equal to 22 (reference), 150, 200, 250 and $273 \mathrm{~N}$. The mean longitudinal strains were measured using the GA-DVC algorithm with an element size of 16 voxels from which a stress-strain curve of the specimen (cross section: $1.6 \times 0.8 \mathrm{~mm}^{2}$ ) was obtained [45]. The same micro-CT scans were used for an analysis using the local approach, LA-DVC, following the procedure described in Section 2.2.1. These values are finally compared with independent studies on the same material [46]. 


\subsection{Finite element modelling}

A volume of interest (VOI) was selected for this study, and resulted in a cube of size $5.12 \mathrm{~mm}$ (256 voxels), extracted from the core of the upper part of the cylinder (Fig. 4). To be comparable to the histograms and the strain maps measured using the DVC methods, the solid phase and the void phase were meshed together. The average strain of the mixture is the sum of the average strains of the solid and void phases.

\subsubsection{Finite element mesh}

The micro-CT scan images of the implant were imported into the Avizo software (Avizo Standard Edition, 6.3.0, VSG, an FEI company, Burlington, USA) to generate unstructured tetrahedral meshes using the methodology described in [47]. The number of elements was fixed to 21,138 so that the average element size, 21 voxels $(0.42 \mathrm{~mm}$, Fig. $4 \mathrm{~b})$, matches as best as possible the DVC cell size, 32 voxels $(0.64 \mathrm{~mm})$, to allow the displacements obtained from FE to be compared with the measured displacements using the DVC methods. Increasing further the element size would reduce the quality of the mesh. A sensitivity analysis, where the number of elements was varied from 21,138 to 502,726 elements $(0.127 \mathrm{~mm}$ element size, Fig. $4 \mathrm{c})$, revealed that the average strains are independent of the mesh density (Fig. 5a), which is essentially attributed to the boundary conditions. The experimental displacements are applied here as boundary conditions on all the external faces of the meshes (Section 2.3.3). According to the theorem of spatial averaging in the homogenisation theory [48], as the volume fraction is preserved in all the meshes, the average strains are unique and similar. The local convergence was reached for an element size of $0.168 \mathrm{~mm}$ (Fig. 5b). Thus, the strain maps obtained with an element size of $0.168 \mathrm{~mm}$ or $0.127 \mathrm{~mm}$ are expected to be more heterogeneous than those obtained with $0.42 \mathrm{~mm}$ (Section 3.3).

\subsubsection{Mechanical properties of the constituents}

The mechanical properties of the solid phase were identified separately after calibration using an inverse method [41]. A linear elastic analysis was first performed up to a nominal apparent strain of 
$0.1 \%$ and the tissue elastic modulus was determined by matching the predicted apparent modulus of the model to the one deduced from the experimental force versus displacement curve (Fig. 2a). Secondly, a nonlinear analysis was carried out to adjust the tissue yield stress by fitting the predicted apparent yield point to the experimental yield stress value using the $0.2 \%$ offset method. The mesh of the solid phase resulted in 437,159 elements and 572,178 nodes. The implant tissue was assumed to be elastic perfectly plastic due to the lack of mechanical data available. Poisson's ratio was assumed to be 0.3 [49], while Young's modulus and yield stress were found to be $600 \mathrm{MPa}$ and 12.5 $\mathrm{MPa}$, respectively. A very soft linear elastic behaviour was chosen for the void phase. The contrast defined as the ratio between Young's moduli of the solid phase and the void phase was fixed to 10,000 .

\subsubsection{Boundary conditions}

The experimental displacements measured by the two DVC methods were separately applied as boundary conditions on the mesh external faces. All the FE analyses were performed on the FE solver COMSOL Multiphysics (COMSOL Multiphysics, 4.2.a, COMSOL Group, Boston, USA), using large deformation to account for geometrical nonlinearity and large rotations.

\section{Results}

\subsection{Performance study}

The average displacements computed over the VOI (Fig. 4) and the standard displacement/strain uncertainties (Table 1 and Fig. 6) are shown as functions of the prescribed displacement. The correlation coefficient is extremely good $\left(r_{L A-D V C}=0.99\right.$ and $\left.r_{G A-D V C} \approx 0\right)$ for all the computations as a simple rigid body motion is prescribed with no additional noise. With the increase of the prescribed displacement, the systematic error of the local correlation method varies between 0.005 voxel $(0.1$ $\mu \mathrm{m})$ to 0.016 voxel $(0.32 \mu \mathrm{m})$, while that of the global correlation method is less than 0.00012 voxel $(0.0024 \mu \mathrm{m})$. Displacement uncertainties ranging between 0.006 voxel $(0.12 \mu \mathrm{m})$ and 0.02 voxel $(0.4$ $\mu \mathrm{m})$ are observed for both approaches using a sub-volume of size 32 voxels or an element size of 16 
voxels. The highest displacement uncertainty is reached for the prescribed displacement of 0.5 voxel. Before correlation, the artificial images were shifted and interpolated in the sub-voxel region using FFT. This kind of interpolation is known to introduce small errors that increase with the shift level, with a maximum reached when the shift comes close to half a voxel $[7,11,50]$.

When increasing the element size, from 16 voxels to 32 voxels, the impact on the systematic error is negligible and the displacement uncertainty is reduced by a factor of 4 . The strain uncertainty is decreased by a factor of 9 and is two times lower than that of the local approach, which ranges between $60 \mu \varepsilon$ and $200 \mu \varepsilon$. Since the displacement estimates are biased for the local approach, the strain uncertainty estimates are lower bounds [51]. Increasing the correlation window of the local approach reduces slightly the displacement and strain uncertainties. Interestingly, increasing the number of intermediary sub-volumes during the multi-pass approach allows us to reduce the displacement uncertainty by a factor of about 4 , and the strain uncertainty by a factor of about 3 (Fig. 7), even though the systematic error does not vary.

To validate the reported strain measurements accuracy, the stress-strain curve of a nodular graphite cast iron was deduced from the DVC analysis of five micro-CT scans (Fig. 8). A very good agreement is observed for both DVC methods. The reported displacement uncertainty can reach up to 0.02 voxel using a sub-volume size of 32 voxels or an element size of 16 voxels. The corresponding standard uncertainty of the mean longitudinal strain, derived from [45], is less than $10^{-5}$ for the local and global approaches, which is much lower than the measured levels. The identified value of Young's modulus is $156 \mathrm{GPa}$ using the global approach and $155 \mathrm{GPa}$ using the local approach, which is very close to published values of the same material (160 $\pm 3 \mathrm{GPa}[46])$.

\subsection{Displacement measurements}

\subsubsection{Correlation quality}

The histograms of the correlation coefficient, $r_{L A-D V C}$, and the correlation residual, $r_{G A-D V C}$, are represented in Figs. 9a and 10a, respectively. All the curves are bell-shaped with a pronounced peak. 
The mean value and standard deviation of each distribution are reported in Table 2. The overall quality of the correlation is very satisfactory with a sub-volume size of 32 voxels ( $\mu^{r_{L A-D V C}}=0.96$, $\left.\sigma^{r_{L A-D V C}}=0.015\right)$ or an element size of 16 voxels $\left(\mu^{r_{G A-D V C}}=0.02, \sigma^{r_{G A-D V C}}=0.018\right)$. The results with a final sub-volume of size 32 voxels are obtained after a previous pass with a 64 voxels sub-volume size, which improves the correlation quality (Table 2) and illustrates the benefit of using the multipass approach. For GA-DVC, as the element decreases in size, more degrees of freedom are available to reduce the correlation residual. This effect is clearly seen when comparing Figs. 10b and 10c. The mean residual reached for 16 voxel elements is equal to $2 \%$ of the dynamic range versus $2.8 \%$ for 32 voxel elements, which indicates that the matching is better for small size elements. This effect is typical of localised phenomena [8].

The maps of the correlation coefficient, $r_{L A-D V C}$, and the correlation residual, $r_{G A-D V C}$, are represented in Figs. 9b,c and Figs. 10b,c, respectively. For the local approach, the correlation coefficient is smaller in regions at the top of the sample where the deformation is the highest. Elsewhere, the correlation coefficient is very high and continuously distributed, especially with a sub-volume size of 32 voxels. For the global approach, the correlation residuals are not only small on average but also locally. The highest correlation residuals seem to be homogenously distributed over the region of interest, which is likely to be attributed to the noise level [5].

\subsubsection{Displacement maps}

The effect of cell size on the vertical displacement distribution was assessed for the two DVC methods before the analysis (Fig. 11). When decreasing the cell size, the convergence of LA-DVC was reached after 48 voxels while faster convergence was observed for GA-DVC. As a precaution, a subvolume or element size of 32 voxels was used. This size is the most suitable for a detailed comparison of the strain fields (Section 3.3) as similar strain uncertainties are obtained with this size, using both approaches (Fig. 6b), and with a good correlation quality (Figs. 9 and 10). The displacement maps obtained on the VOI are represented in Figure 12. Similar results are obtained 
between the two correlation techniques. The vertical displacement map (Fig. 12c) reveals that the compression is not symmetric with respect to the loading axis $(\mathrm{Oz})$. The sample has probably slightly rotated along (Oy) during the experiment. The lateral displacement maps (Figs. 12a and 12b) also indicate that twisting of the sample has occurred in the (xy) plane during the experiment.

\subsection{Comparison of the strain fields}

Figure 13 depicts the histograms of the axial strain, $\varepsilon_{z z}$, and the lateral strains, $\varepsilon_{x x}$ and $\varepsilon_{y y}$. For each strain component, similar distributions are observed for both DVC methods and they compare well with the FE results. All the curves are bell-shaped, and asymmetric with respect to the mean value. This asymmetry is probably a consequence of the misalignment of the sample as illustrated by the displacement maps. Each distribution was characterised by its mean value and standard deviation, as summarised in Table 3, and the results compare well with each other. The maximum error, calculated as the absolute value of the difference between the mean strains obtained by the two DVC methods, is $0.08 \%$. The mean strains obtained with the FE model are also independent of the mesh size, although slightly more scatter is observed when decreasing the mesh size (Fig. 13d and Table 3). For each DVC method, the mean strains and standard deviations compare well with the corresponding FE model (maximum error: LA-DVC 0.04\%; GA-DVC 0.01\%). The vertical strain maps obtained by the two DVC methods are illustrated in Figure 14, and similar results are obtained. The levels of the lateral strains are similar and omitted here for clarity. Highly localised vertical strain is evident near the top (Fig. 14c), similar to the lateral strains (Fig. 15c). Elsewhere, the strains obtained by DVC seem to be lower and more continuously distributed. The strain maps predicted by the FE analysis with an average element size of $0.42 \mathrm{~mm}$ are similar to the DVC measured strains (Figs. $14,15 \mathrm{c}$ vs. $15 \mathrm{e}$ and $16 \mathrm{c}$ vs. $16 \mathrm{e}$ ). Decreasing the average mesh size to $0.127 \mathrm{~mm}$ would lead to more local heterogeneity of the strain distributions (Figs. $15 \mathrm{c}$ vs. $15 \mathrm{~d}$ and $16 \mathrm{c}$ vs. $16 \mathrm{~d}$ ). 


\section{Discussion}

The use of FFT, combined with the multi-pass approach in the local correlation algorithm (LA-DVC), allowed fast calculations with systematic errors or displacement bias ranging between 0.0052 voxel $(0.104 \mu \mathrm{m})$ and 0.0129 voxel $(0.258 \mu \mathrm{m})$, standard displacement uncertainties ranging between 0.006 voxel $(0.12 \mu \mathrm{m})$ and 0.02 voxel $(0.4 \mu \mathrm{m})$ and strain uncertainties ranging between 60 and $200 \mu \varepsilon$, with a correlation window of 32 voxels $(640 \mu \mathrm{m})$. The performance compares well with the data reported in the literature $[4,6,9,19,21]$, where the displacement uncertainty ranged between 0.009 and 0.094 voxel $(0.315$ and $3.39 \mu \mathrm{m})$ and the strain uncertainty ranged between 100 and $800 \mu \varepsilon$, using local DVC algorithms. The global correlation method, GA-DVC, gives similar displacement uncertainties but lower systematic errors are obtained (below 0.00012 voxel. i.e. $0.0024 \mu \mathrm{m})$, independent of the element size. Increasing the number of intermediary sub-volumes using the local approach reduces the displacement and the strain uncertainties by a factor of 4 and 3 , respectively. The same levels of displacement and strain accuracies can also be achieved using the global approach by simply increasing the size of the element. Solutions may be developed to reduce the displacement uncertainty of the local correlation algorithm LA-DVC, such as taking into account higher-order displacement gradients during the multi-pass approach, improving further the peakfinding algorithm [52] or reducing the numerical artefacts generated by FFTs [53]. On the other hand, this study reveals that the requirement of global displacement continuity, provided by the GADVC algorithm, appears to be one of the keys in significantly reducing both displacement uncertainty and systematic error $[11,28,29,54]$ when compared to FFT-based local approaches.

The quality of the correlation results was very satisfactory for both DVC methods and the accuracy of the reported strain measurements was validated against the experimental Young's modulus of a model material. The strain uncertainties are also much lower than the mean strain values (between 0.9 and $1.8 \%)$. In addition, the strain maps and histograms obtained with the local correlation approach are in a good agreement with those obtained with the global approach. This indicates that 
the image registration performed by the two DVC methods was successful and that the measured displacements and strains are reliable. Both correlation techniques predicted highly localised strains at exactly the same region (top end of the sample). Collapse of the foam cells was observed precisely in this zone after compressing the sample to $-6 \%$ strain (see Fig. 2). The occurrence of localised strains at the top might be due to end artefacts, which may be removed by fixing both ends of the sample with pre-aligned end-caps [1] to prevent the sample from bending or twisting and to allow deformation to occur preferentially at the midsection.

The FE method predicts mean strains and standard deviation in the axial and lateral directions that are similar to those measured using both DVC methods. Note that the length scale of the local displacement measurements in the DVC methods $(0.64 \mathrm{~mm})$ is five times larger than the mean size of an individual strut $(0.15 \mathrm{~mm}+/-0.04 \mathrm{~mm})$ and three times larger than the mean size of the spacing between the struts [55]. Therefore, the DVC methods assume the struts to be a continuum medium. The FE model with an average mesh size of $0.127 \mathrm{~mm}$ is able to operate at the strut level. Although the mean strain values compare well with the DVC methods, the FE strain maps reveal, logically, more local heterogeneity. By increasing the average mesh size of the FE model to 1.5 times the size of the DVC correlation window $(0.42 \mathrm{~mm}$ vs $0.64 \mathrm{~mm})$, to reduce the resolution of the $\mathrm{FE}$ displacements at a level comparable to DVC methods, similar strain maps may be obtained. In [21], smaller lateral deformations were predicted than measured using DVC. In addition to the limitations addressed by the authors, another assumption might be added to explain such a difference. The presence of apparent localisation observed from the DVC strain map at the top of the bone sample (along the lateral direction), seems not to be entirely captured by the FE model. This might reflect the need for using DVC displacements to constrain also the lateral faces in order to catch properly this localisation.

The present analysis offers a tool for accurately determining the mechanical properties of porous scaffold materials in clinical applications of musculoskeletal tissue engineering [56]. For example, in 
vivo bone compressive strains in the knee can range from $414 \mu \varepsilon$ during walking up to $2000 \mu \varepsilon$ during vigorous activities [57]. These values are much higher than the DVC strain uncertainties and thus both DVC techniques are viable to characterise the mechanical properties of scaffolds within the physiological strain range. The proposed method can also be used for trabecular bones and might have some clinical significance in better predicting the risk for osteoporotic fracture [39]. The use of realistic boundary conditions in the models might produce more accurate description of the internal deformation hence improve the predictions of the stiffness and strength currently available $[21,38,39]$

\section{Conclusions}

This paper compares 3D full-field displacements in a porous scaffold material measured using two digital volume correlation methods and predicted with finite element simulations. The results demonstrate that both DVC methods are applicable to the porous material and the measured displacements and strains compare well between the two DVC methods, and with those obtained from the FE model. One key ingredient for this agreement is related to the fact that measured boundary conditions were applied to the numerical models. For applications where displacement uncertainties of 0.02 voxel $(0.4 \mu \mathrm{m})$ and strain uncertainties of the order of $200 \mu \varepsilon$ are acceptable, the local approach is appropriate and gives a good compromise between accuracy and computational cost. For applications where small strain levels and both low systematic error and low displacement uncertainty are required (below 0.02 voxel) with the same level of strain uncertainty, the global approach is a good alternative. Lastly, these displacement (and strain) measurement techniques seem to be promising for a range of applications in biomedical engineering.

\section{Acknowledgements}

The authors would like to acknowledge Smith \& Nephew for providing the samples. This work is partially funded by the Higher Education Innovation Fund (HEIF4). 


\section{Conflict of interest statement}

The authors confirm that no conflict of interest is related to the enclosed manuscript.

\section{Ethical approval}

Not required.

\section{References}

[1] Nazarian A, Müller R. Time-lapsed microstructural imaging of bone failure behavior. J Biomech 2004;37(1):55-65.

[2] Youssef S, Maire E, Gaertner R. Finite element modeling of the actual structure of cellular materials determined by X-ray tomography. Acta Mat 2005;53(3):719-30.

[3] Buffière J-Y, Maire E, Adrien J, Masse J-P., Boller E. In Situ Experiments with X ray Tomography: an Attractive Tool for Experimental Mechanics. Exp Mech 2010;50(3):289-05.

[4] Bay BK, Smith TS, Fyrhie DP, Saad M. Digital Volume Correlation: three-dimensional strain mapping using X-ray tomography. Exp Mech 1999;39(3):217-26.

[5] Benoit A, Guerard S, Gillet B, Guillot G, Hild F, Mitton D, Périé J-N, Roux S. 3D analysis from microMRI during in situ compression on cancellous bone. J Biomech 2009;42(14):2381-6.

[6] Bornert M, Chaix JM, Doumalin P, Dupré JC, Fournel T, Jeulin D, Maire E, Moreaud M, Moulinec H. Mesure tridimensionnelle de champs cinématiques par imagerie volumique pour l'analyse des matériaux et des structures. Instrum Mes Metrol 2004;4(3):43-88.

[7] Germaneau A, Doumalin P, Dupré JC. 3D strain field measurement by correlation of volume images using scattered light: recording of images and choice of marks. Strain 2007;43(3):20718.

[8] Hild F, Maire E, Roux S, Witz J-F. Three dimensional analysis of a compression test on stone wool. Acta Mat 2009;57(11):3310-20. 
[9] Liu L, Morgan EF. Accuracy and precision of digital volume correlation in quantifying displacements and strains in trabecular bone. J Biomech 2007;40(15):3516-20.

[10] Rannou J, Limodin N, Réthoré J, Gravouil A, Ludwig W, Baïetto-Dubourg M-C, Buffière J-Y, Combescure A, Hild F, Roux S. Three dimensional experimental and numerical multiscale analysis of a fatigue crack. Comp Meth Appl Mech Eng 2010;199(21):1307-25.

[11] Roux S, Hild F, Viot P, Bernard D. Three-dimensional image correlation from X-ray computed tomography of solid foam. Compos Part A 2008;39(8):1253-65.

[12] Verhulp E, Van Rietbergen B, Huiskes R. A three-dimensional Digital Image Correlation technique for strain measurements in microstructures. J Biomech 2004;37(9):1313-20.

[13] Sutton MA, Wolters WJ, Peters WH, Ranson WF, McNeill SR. Determination of displacements using an improved digital correlation method. Im Vis Comp 1983;1(3):133-9.

[14] Peters WH, Ranson WF. Digital Imaging Techniques in Experimental Stress Analysis. Opt Eng $1982 ; 21(3): 427-32$.

[15] Bay BK. Texture correlation - a method for the measurement of detailed strain distributions within trabecular bone. J Orthop Res 1995;13(2):258-67

[16] Sjödahl M, Benckert LR. Electronic speckle photography: analysis of an algorithm giving the displacement with subpixel accuracy. Appl Opt 1993;32(13):2278-84.

[17] Luo PF, Chao YJ, Sutton MA, Peters WH. Accurate measurement of three-dimensional displacement in deformable bodies using computer vision. Exp Mech 1993;33(2):123-32

[18] Helm JD, McNeil SR, Sutton MA. Improved three-dimensional image correlation for surface displacement measurement. Opt Eng 1996;35(7):1911-20

[19] Bay BK. Experimental measurement of three dimensional continuum-level strain fields in trabecular bone. Adv Expl Med Biol 2001;496:181-97.

[20] Smith TS, Bay BK, Rashid MM. Digital Volume Correlation including rotational degrees of freedom during minimization. Exp Mech 2002;42(3):272-8. 
[21] Zauel R, Yeni YN, Bay BK, Dong XN, Fyhrie DP. Comparison of the linear finite element prediction of deformation and strain of human cancellous bone to 3D Digital Volume Correlation measurements. J Biomech Eng 2006;128(1):1-6.

[22] Lenoir N, Bornert M, Desrues J, Bésuelle P, Viggiani G. Volumetric digital image correlation applied to X-ray microtomography images from triaxial compression tests on argillaceous rock. Strain 2007;43(3):193-05.

[23] Forsberg F, Sjodahl M, Mooser R, Hack E, Wyss P. Full Three-dimensional strain measurements on wood exposed to three-point bending: analysis by use of digital volume correlation applied to synchrotron radiation micro-computed tomography image data. Strain 2010;46(1):47-60.

[24] Germaneau A, Doumalin P, Dupré J-C. Comparison between X-ray micro-computed tomography and optical scanning tomography for full 3D strain measurement by digital volume correlation. NDT\&E International 2008;41(6):407-15.

[25] Scarano F, Riethmuller M. Advances in iterative multigrid PIV image processing. Exp Fluids 2000;29(7):51-60.

[26] Cheng P, Sutton MA, Schreier HW, McNeill SR. Full-field speckle pattern image correlation with B-spline deformation function. Exp Mech 2002;42(3):344-52.

[27] Sun Y, Pang JHL., Wong CK, Su F. Finite element formulation for a digital image correlation method. Appl Opt 2005;44(34):7357-63

[28] Hild F, Roux S. Digital Image Correlation: from displacement measurement to identification of elastic properties - a Review. Strain 2006;42(2):69-80.

[29] Hild F, Roux S. Comparison of Local and Global Approaches to Digital Image Correlation. Exp Mech 2012; 52(9):1503-19.

[30] Saadatfar M, Arns CH, Knackstedt MA, Senden T. Mechanical and Transport Properties of Polymeric Foams Derived from 3D Images. Coll Surf A 2004;263(1-3):284-9. 
[31] Fischer F, Lim GT, Handge UA, Altstadt V. Numerical Simulation of Mechanical Properties of Cellular Materials Using Computed Tomography Analysis. J Cell Plast 2009;45(5):441-60.

[32] Youssef S, Maire E, Gaertner R. Finite element modeling of the actual structure of cellular materials determined by X-ray tomography. Acta Mater 2005;53(3):719-30.

[33] Singh R, Lee PD, Lindley TC, Kohlhauser C, Hellmich C, Bram M, Imwinkelried T, Dashwood RJ. Characterization of the deformation behavior of intermediate porosity interconnected Ti foams using micro-computed tomography and direct finite element modeling. Acta Biomater $2010 ; 6(6): 2342-51$

[34] Jones JR, Lee PD, Hench LL. Hierarchical porous materials for tissue engineering. Philos Transact A Math Phys Eng Sci 2006;364(1838):263-81.

[35] Lacroix D, Planell JA, Prendergast PJ. Computer-aided design and finite-element modelling of biomaterial scaffolds for bone tissue engineering. Philos Transact A Math Phys Eng Sci 2009;367(1895):1993-09.

[36] Hollister SJ, Brennan JM, Kikuchi N. A homogenization sampling procedure for calculating trabecular bone effective stiffness and tissue level stress. J Biomech 1994;27(4):433-44.

[37] Müller R, Rüegsegger P. Three-dimensional finite element modelling of non-invasively assessed trabecular bone structures. Med Eng Phys 1995;17(2):126-33.

[38] Van Rietbergen B, Weinans H, Huiskes R, Polman BJW. Computational strategies for iterative solutions of large FEM applications employing voxel data. Int J Num Meth Eng 1996;39(16):2743-67.

[39] Yeni YN, Fyhrie DP. Finite element calculated uniaxial apparent stiffness is a consistent predictor of uniaxial apparent strength in human vertebral cancellous bone tested with different boundary conditions. J Biomech 2001;34(12):1649-54.

[40] Niebur GL, Yuen JC, Hsia AC, Keaveny TM. Convergence behavior of high-resolution finite element models of trabecular bone. J Biomech Eng 1999;121(6):629-35. 
[41] Verhulp E, Van Rietbergen B, Muller R, Hsuiskes R. Micro-finite element simulation of trabecular-bone post-yield behaviour--effects of material model, element size and type. Comput Meth Biomech Biomed Eng 2008;11(4):389-95.

[42] Slivka MA, Leatherbury NC, Kieswetter K, Niederauer GG. Porous, Resorbable, Fiber- Reinforced Scaffolds Tailored for Articular Cartilage Repair. Tissue Eng 2001;7(6):767-80.

[43] Tozzi G, Zhang QH, Tong J. 3D real-time micromechanical compressive behaviour of bonecement interface: experimental and finite element studies. J Biomech 2012;45(2):356-63.

[44] Quinta DA Fonseca J, Mummery PM, Withers PJ. Full-field strain mapping by optical correlation of micrographs acquired during deformation. J Microscopy 2005;218:9-21.

[45] Réthoré J, Limodin N, Buffière J-Y, Hild F, Ludwig W, Roux S. Digital volume correlation of synchrotron tomographic images. J Strain Analysis 2011;46:683-95.

[46] Dierickx, P. Etude de la microstructure et des mécanismes d'endommagement des fontes G.S. ductiles: influence des traitements thermiques de ferritisation. PhD Thesis, INSA de Lyon, France, 1996.

[47] Madi K, Forest S, Boussuge M, Gailliegue S, Lataste E, Buffière J-Y, Jeulin D, Bernard D. Finite element simulations of the deformation of fused-cast refractories based on X-ray computed tomography. Comput Mat Sci 2007;39(1):224-9.

[48] M Hori, Nemat-Nasser S. On two micromechanics theories for determining micro-macro relations in heterogeneous solids. Mech Mater 1999;31(10):667-82.

[49] Terrier A, Sedighi-Gilani M, Roshan Ghias A, Aschwanden L, Pioletti DP. Biomechanical evaluation of porous biodegradable scaffolds for revision knee arthroplasty. Comput Meth Biomech Biomed Eng 2009;12(3):333-9.

[50] Inglada J, Muron V, Pichard D, Feuvrier T. Analysis of artifacts in subpixel remote sensing image registration. IEEE Trans Geosci Remote Sens 2007;45(1):254-264. 
[51] Bergonnier S, Hild F, Roux S. Digital image correlation used for mechanical tests on crimped glass wool samples. J Strain An Eng Design 2005;40(2):185-97.

[52] Pan B, Qian K, Xie H, Asundi A. Two-dimensional digital image correlation for in-plane displacement and strain measurement: a review. Meas Sci Technol 2009;20:062001.

[53] Okamoto K. Comparison of sub-pixel estimation of PIV using frequency response analysis. J Visualization 2002;5(4):355-61.

[54] Leclerc H, Périé J-N, Hild F, Roux S. Digital Volume Correlation: What are the limits to the spatial resolution? Mech Indus 2012; in press, DOI: 10.1051/meca/2012025.

[55] Madi K, Booker A, Tozzi G, Zhang Z-Y, Siu Y-H, Lupton C, Tong J, Cossey A, Au A, N'Guyen F. Viscoelastic modelling and full-field strain computation of biphasic scaffold for osteochondral defect repair. ECCOMAS - International Conference on Tissue Engineering P.R. Fernandes et al. (Eds.) Lisbon, Portugal, June 2-4, 2011;117-24.

[56] Henson F, Getgood A. The use of scaffolds in musculoskeletal tissue engineering. Open Orthop J 2011;5:261-6.

[57] Burr DB, Milgrom C, Fyhrie D, Forwood M, Nyska M, Finestone A, Hoshaw S, Saiag E, Simkin A. In vivo measurement of human tibial strains during vigorous activity. Bone 1996;18(5):405-10. 


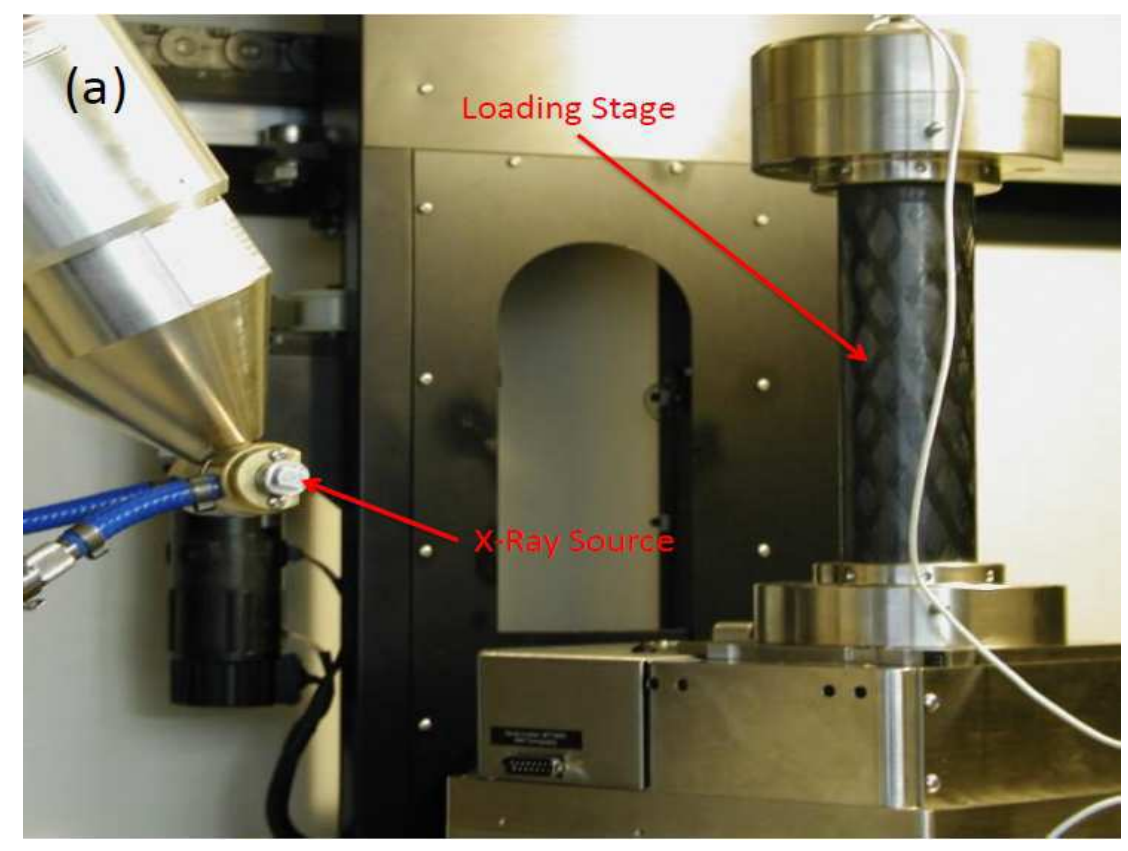

(a)

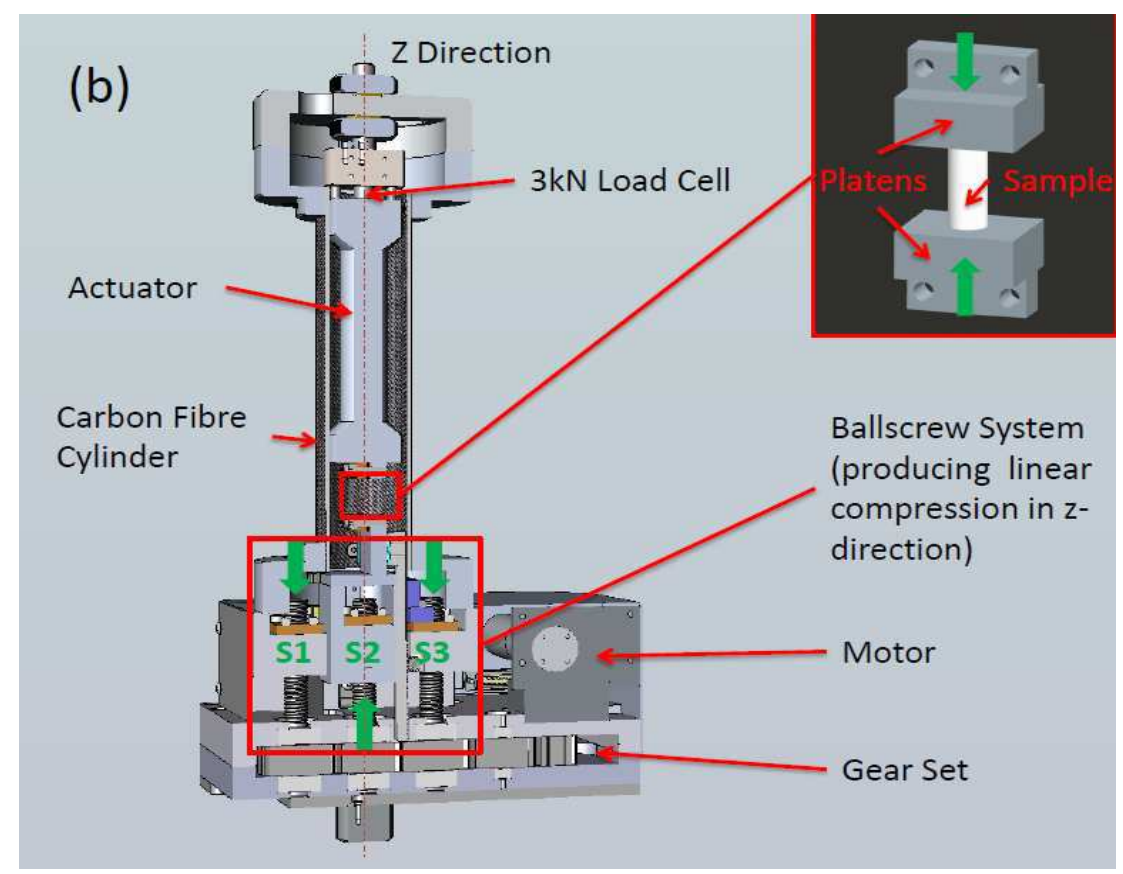

(b)

Fig. 1. (a) The micromechanical testing device positioned in the micro-CT chamber, (b) the linear compression applied to the sample is generated through a ballscrew system $(\mathrm{S} 1, \mathrm{~S} 2, \mathrm{~S} 3)$ that drives the jaws (and consequently the platens) symmetrically in opposite directions. 


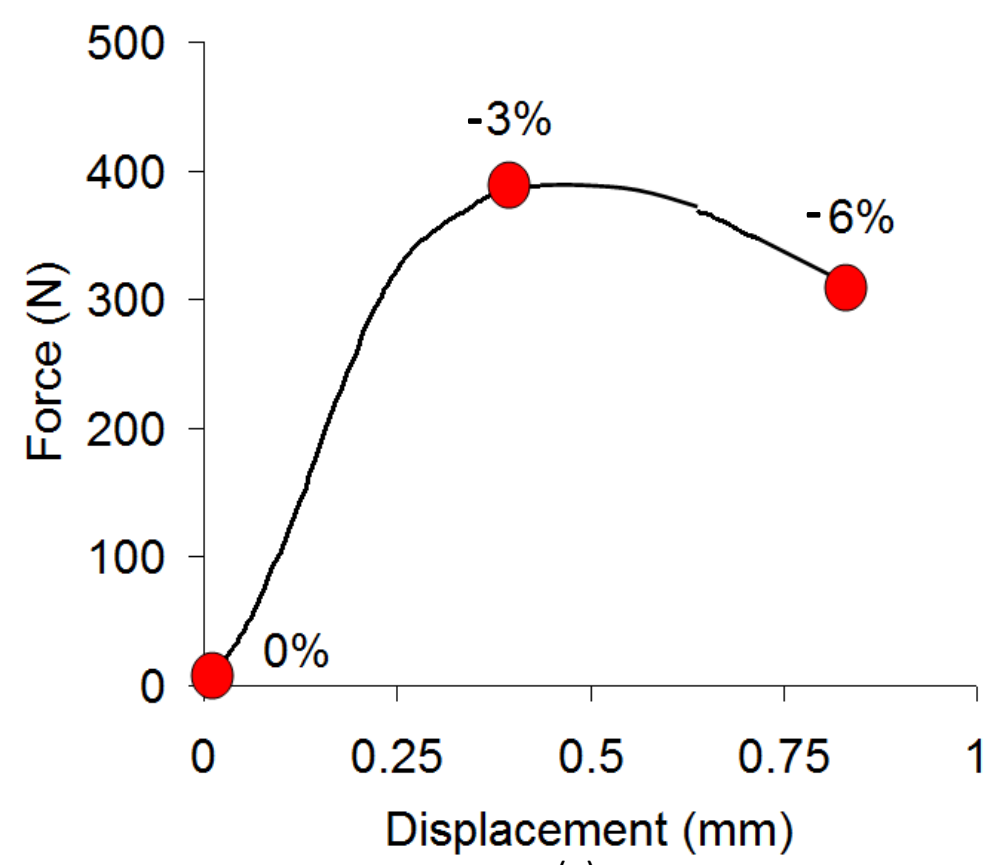

(a)
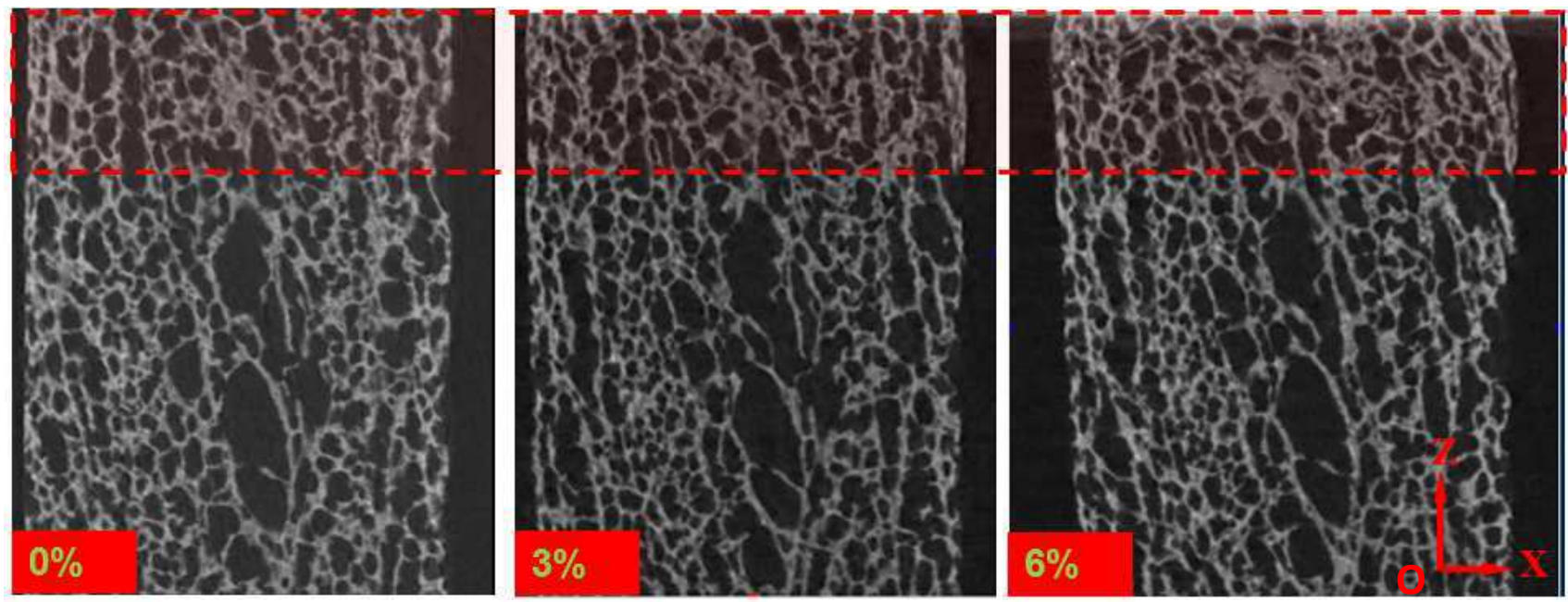

(b)

Fig. 2. (a) Force versus displacement curve obtained after compressing the sample up to $6 \%$ strain (in absolute value), (b) 2D sections extracted at the core of the sample representing the reference $(0 \%$ strain) and deformed morphologies ( $-3 \%$ and $-6 \%$ strains) of the specimen. The sample has been compressed along $(\mathrm{Oz})$ direction. Localised strain, particularly near the top end (dashed box), is evident. 


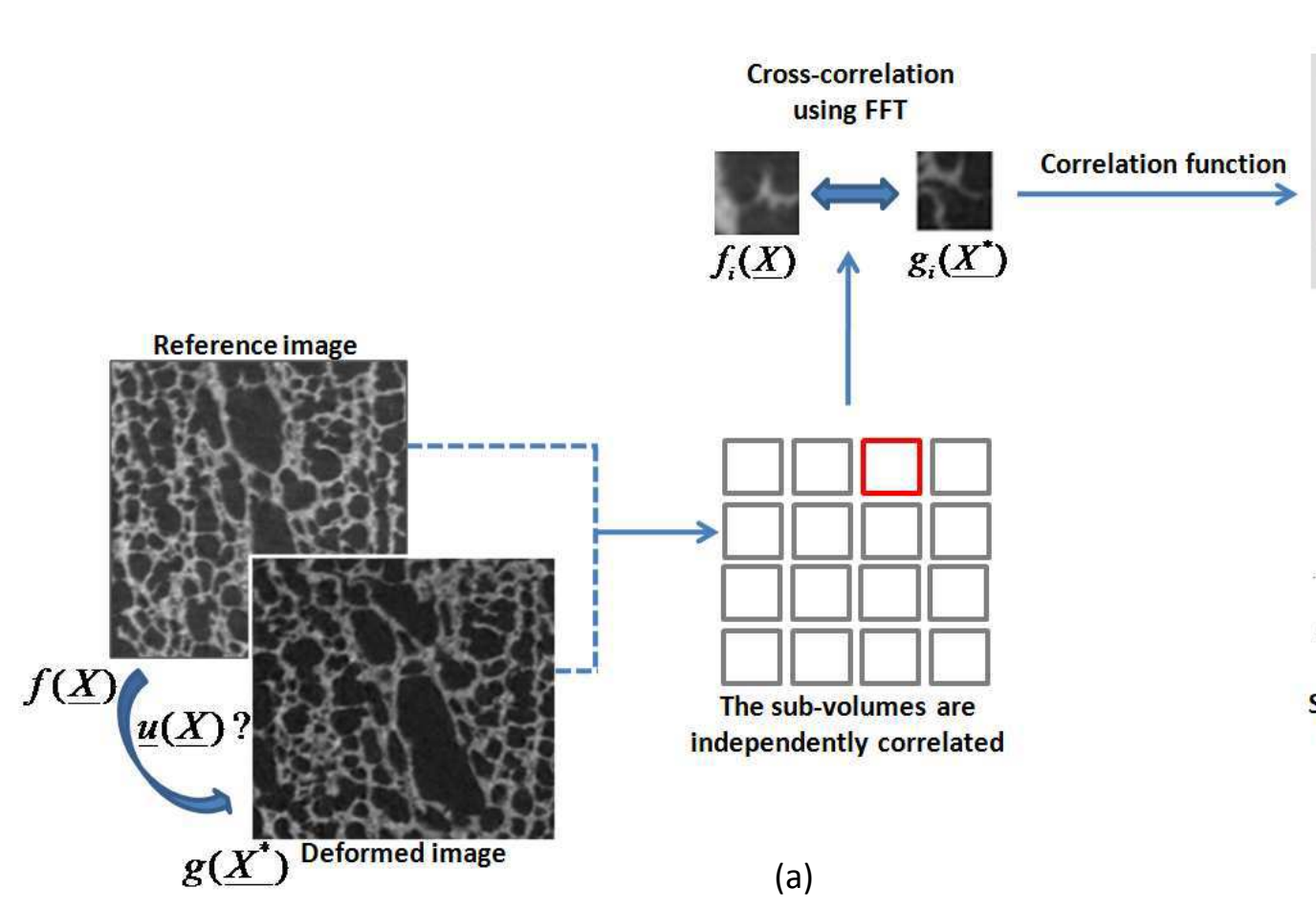

Peak detection

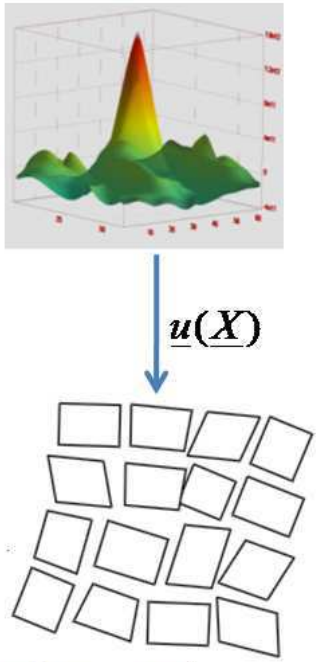

Sub-image grid remapped on the deformed image
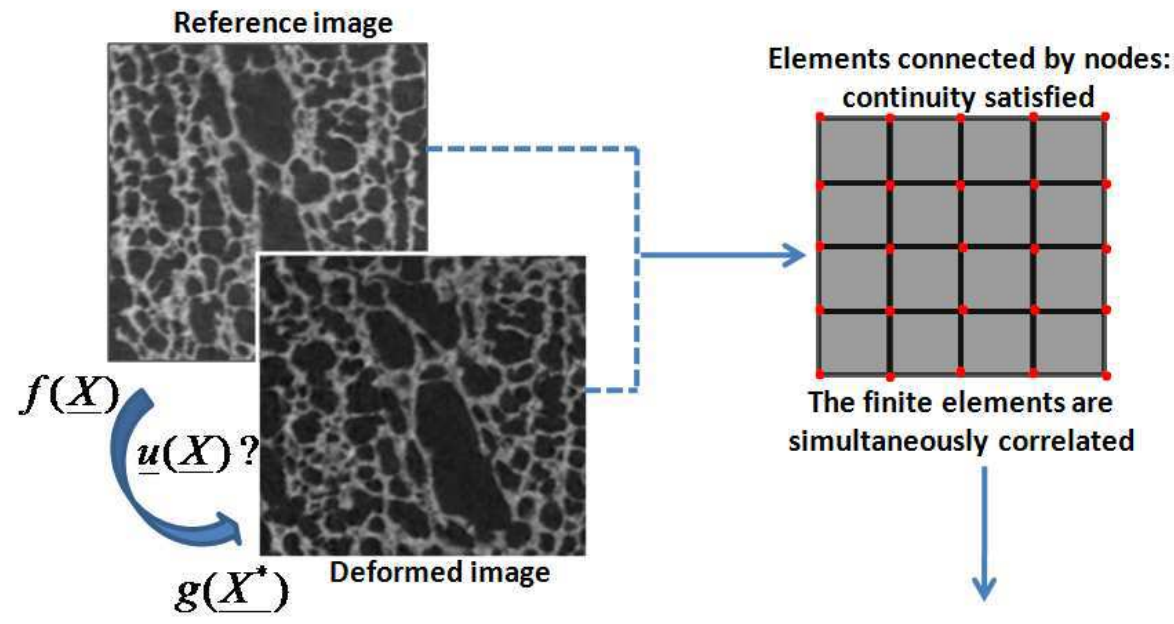

Sub-image mesh remapped on the deformed image

Find $\underline{u}(X)=\sum_{i} a_{i} \underline{\varphi}_{i}(X)$

that minimize the quadratic functional:

$\Phi^{2}\left\{a_{i}\right\}=\iiint_{V}\left[f(\underline{X})-g\left(\underline{X}+a_{i} \underline{\varphi_{i}}(\underline{X})\right)\right]^{2} d \underline{X}$

(b)

Fig. 3. Differences between the FFT-based local approach, LA-DVC [44] (a), and the finite element global approach $[5,11]$, (b). $X$ and $X^{*}$ refer to coordinates (in voxels) of the same point in the reference and the deformed state and $u(X)$ is the sought displacement field; $f$ and $g$ are,

respectively, the grey levels of the initial and deformed volumes. 


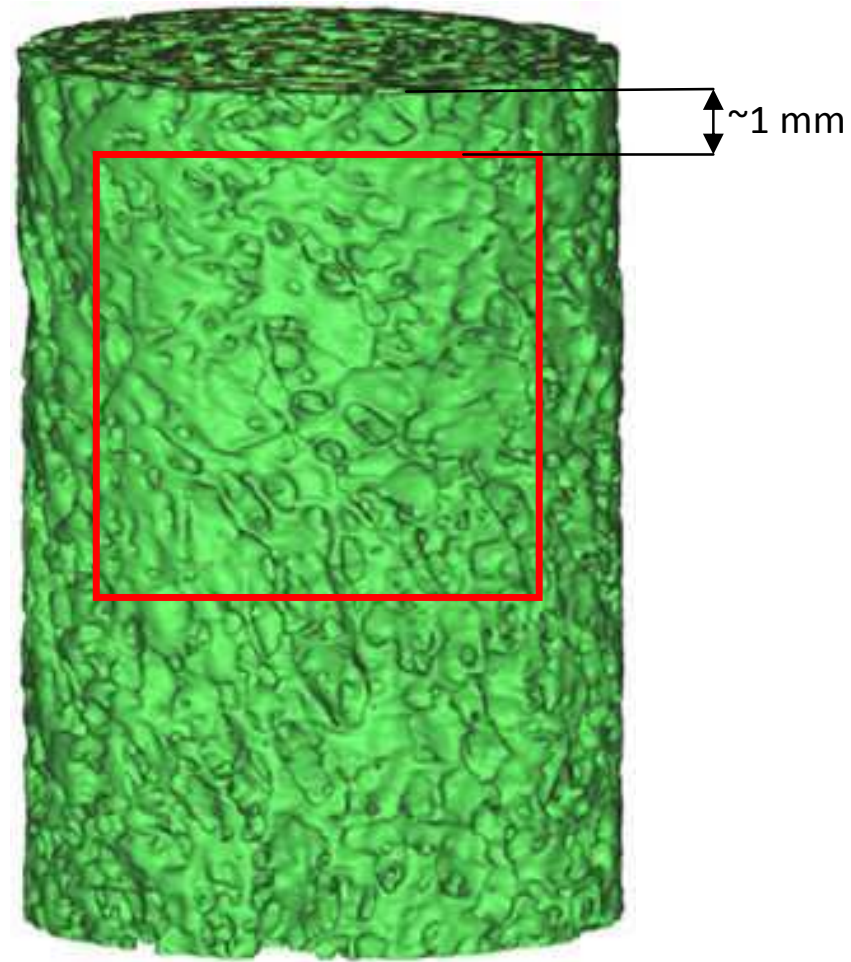

(a)

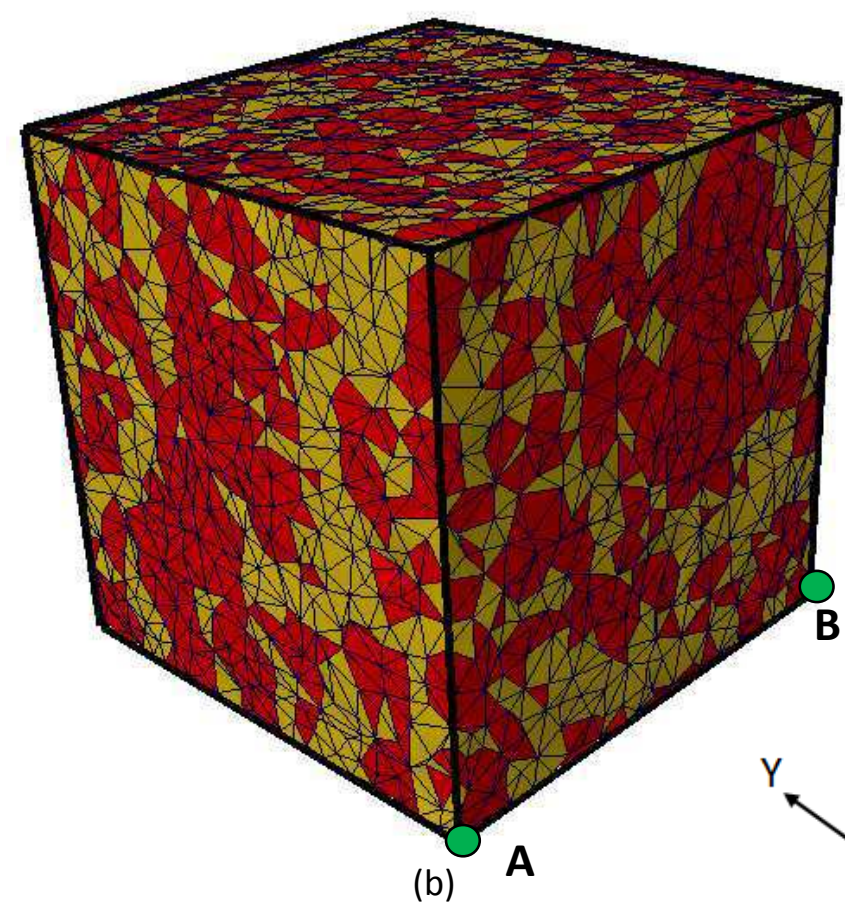

(b)

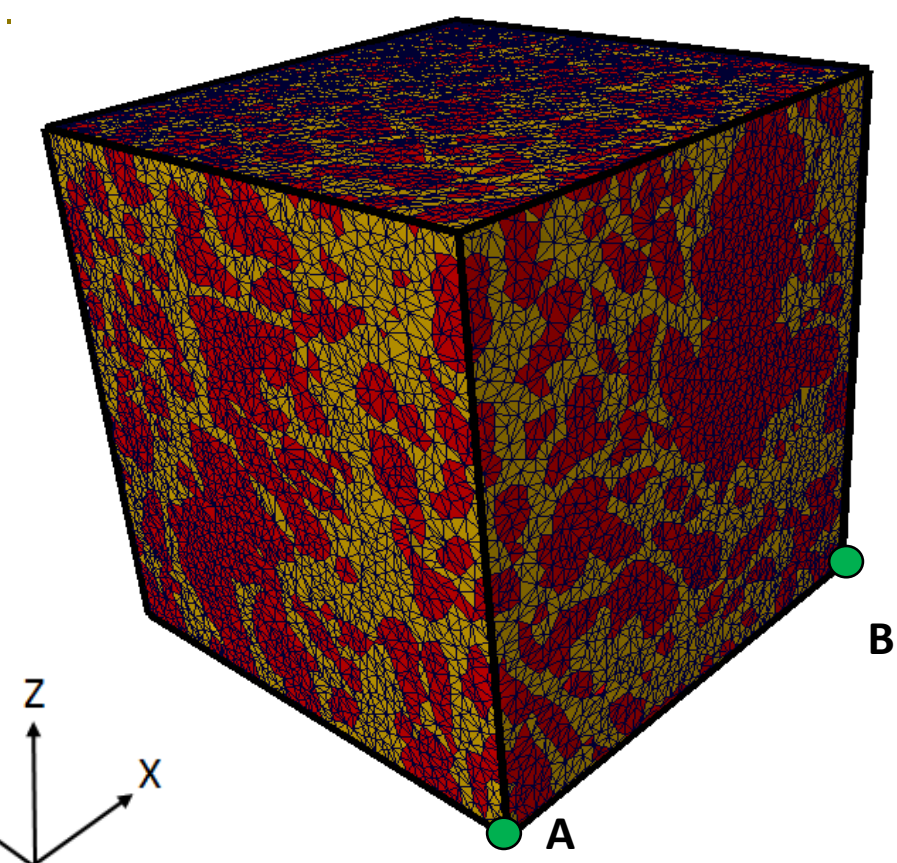

(c)

Fig. 4. (a) 3D reconstruction of the cylindrical specimen (diameter of $8.57 \mathrm{~mm}$ and height of 14.7 $\mathrm{mm}$ ); FE mesh generated from the volume of interest (marked in red in Fig. 4a) with an average element size of $0.42 \mathrm{~mm}$ (21,138 elements), (b) and $0.127 \mathrm{~mm}(502,726$ elements), (c). The solid phase is yellow and the porous phase is red. The volume of interest is a cube of size $5.12 \mathrm{~mm}$. 


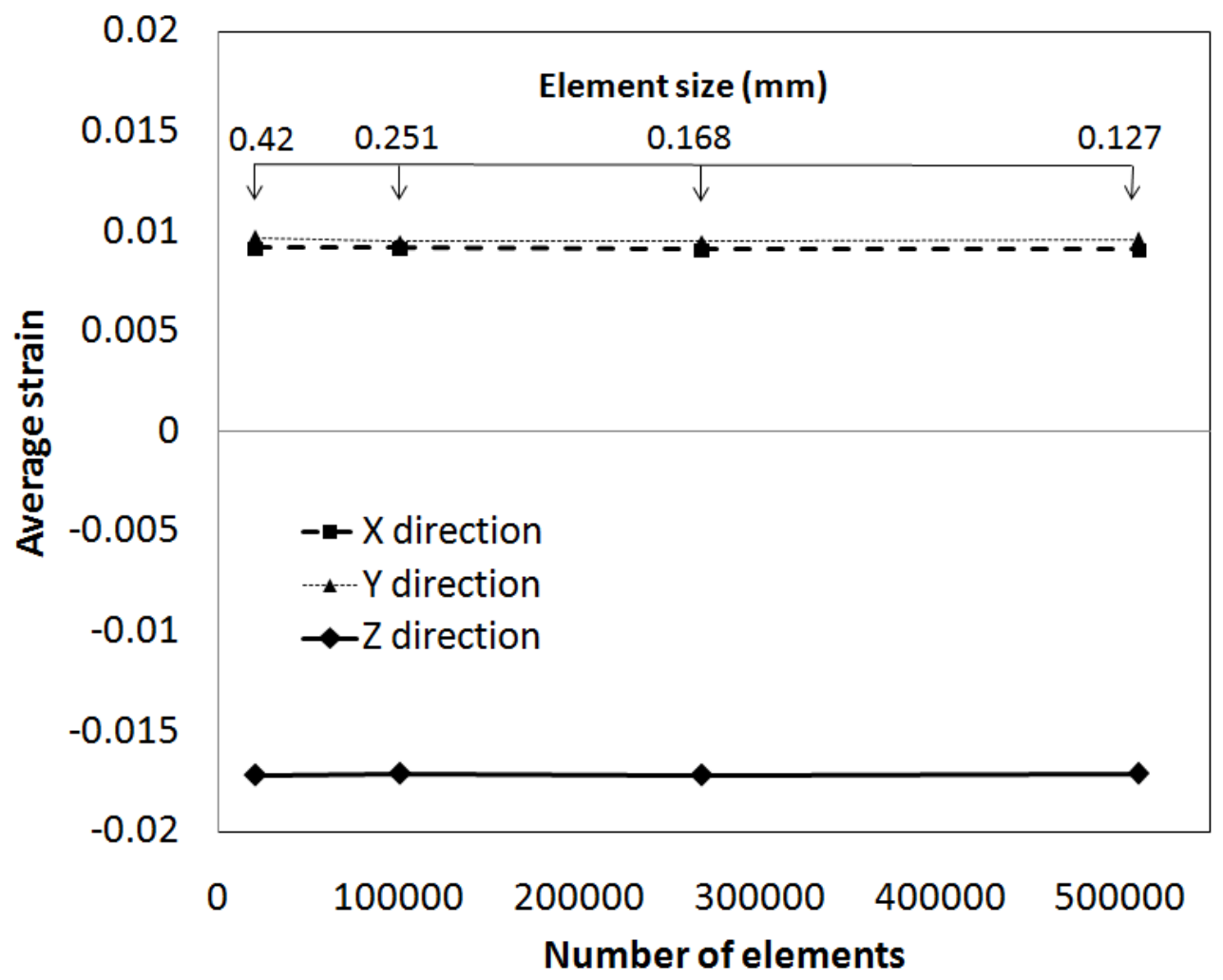

(a)

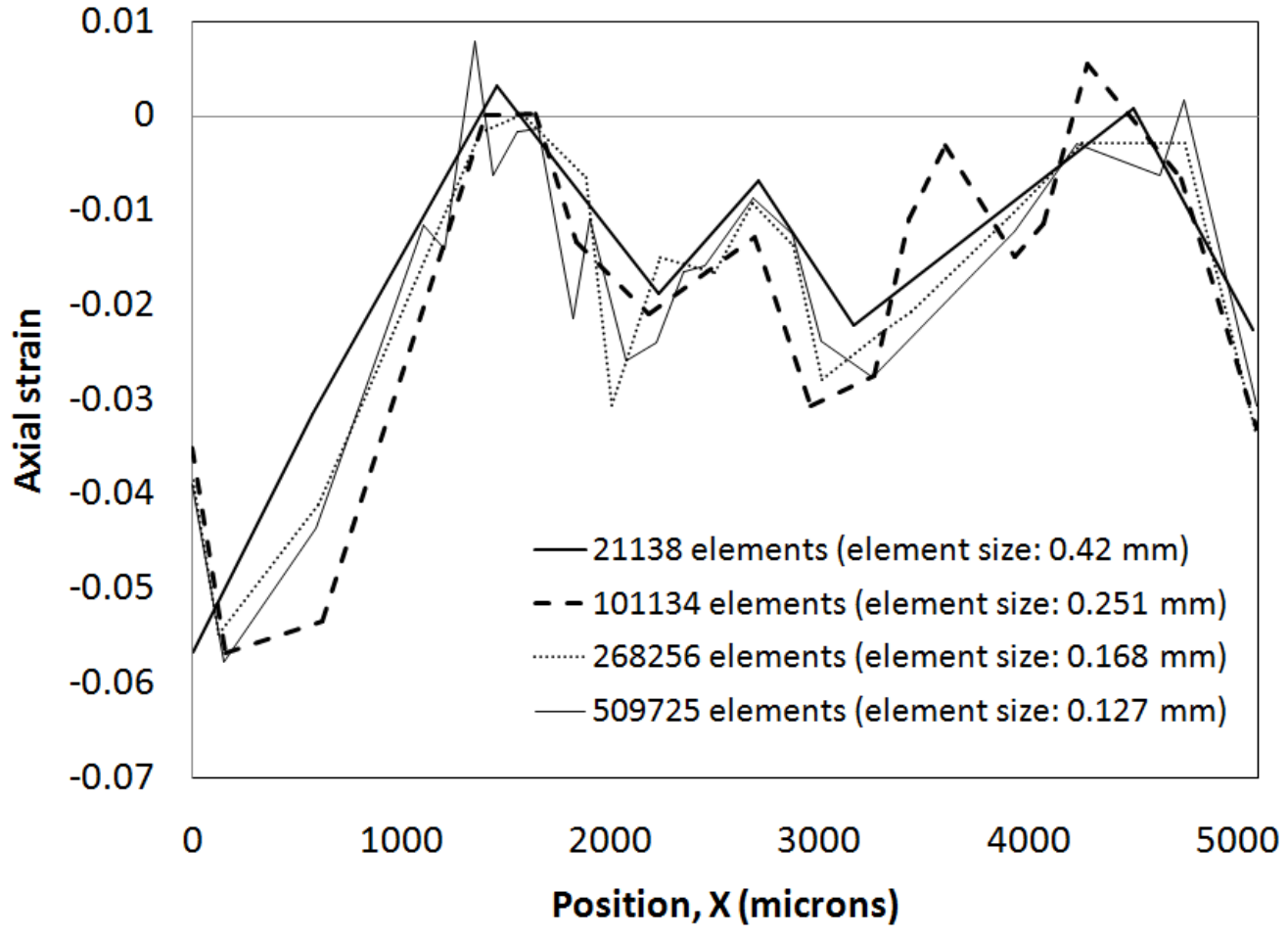

(b)

Fig. 5. The effect of FE mesh density on: (a) the average axial and lateral strains, (b) the local axial strain along one of the VOI edge ( $A B$, see Figs. $4 b$ and $c$ ). Similar results were obtained for LA-DVC and GA-DVC and, for the sake of clarity, only the experimental displacements obtained by LA-DVC were applied as boundary conditions. 


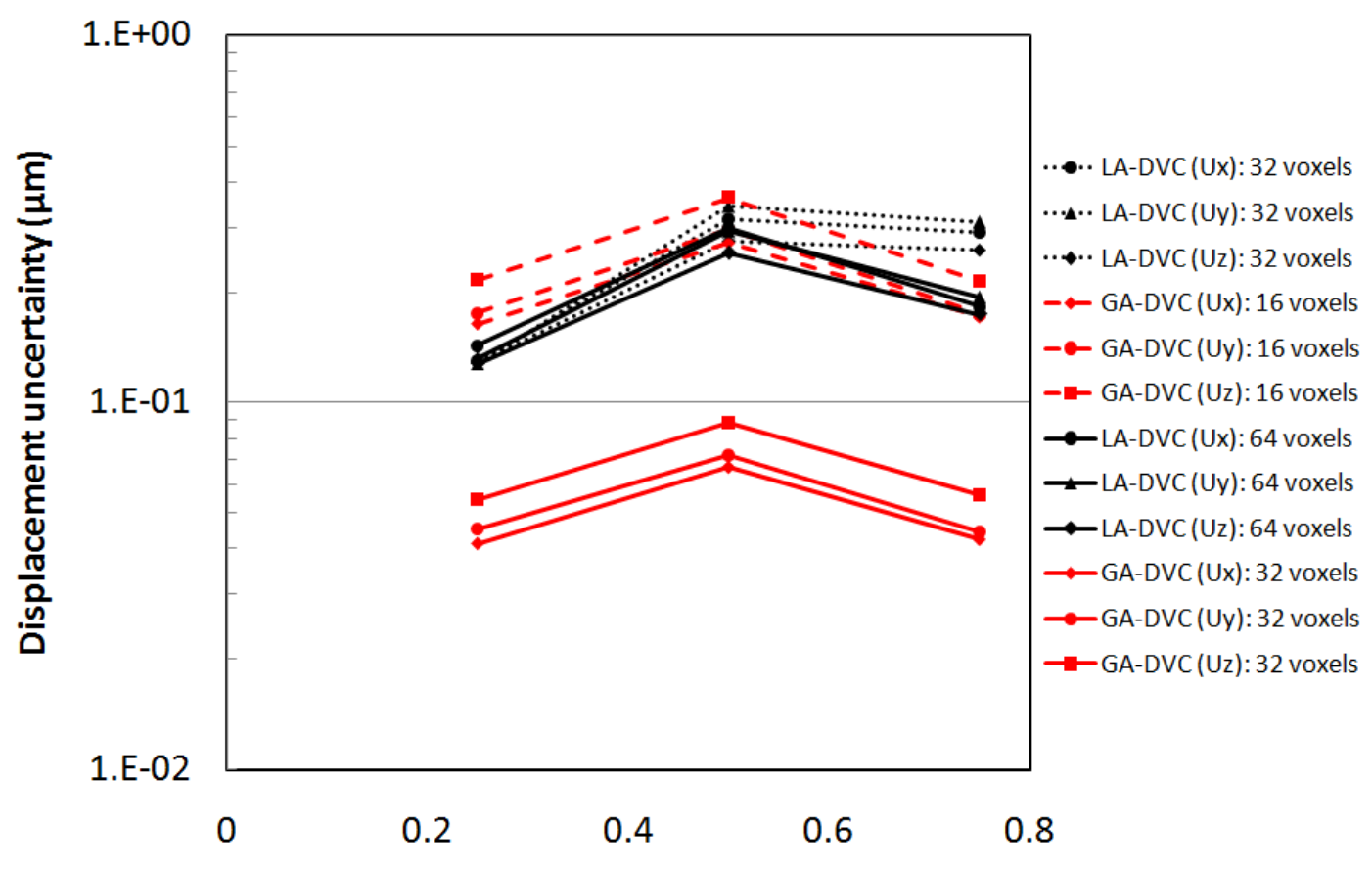

\section{Prescribed displacement (voxel)}

(a)

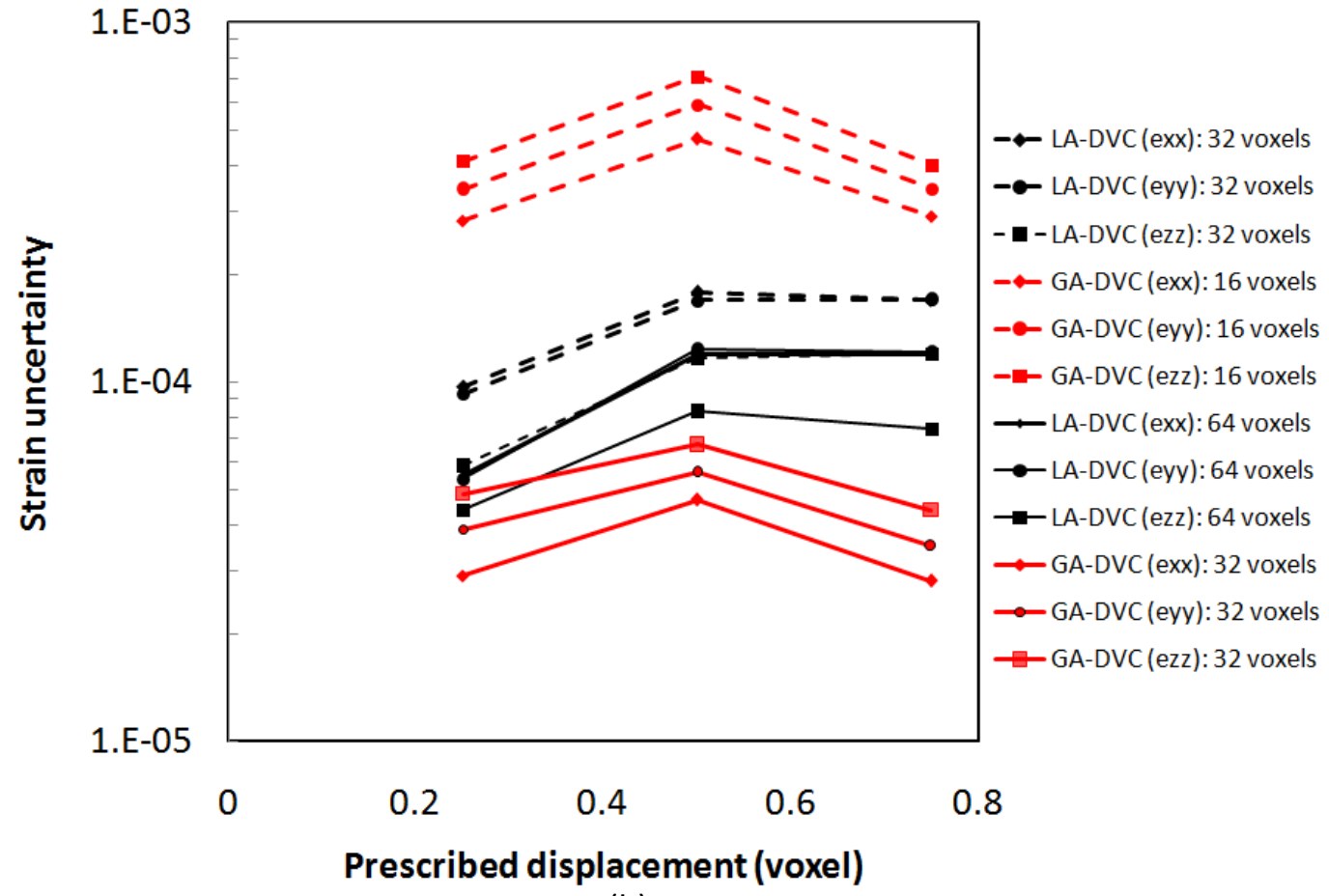

(b)

Fig. 6. Standard displacement uncertainty $\sigma_{u}$ (a), and standard strain uncertainty $\sigma_{\varepsilon}$ (b), as a function of the prescribed displacement for the two correlation techniques (correlation window: 32 and 64 voxels, i.e. 0.64 and $1.28 \mathrm{~mm}$, respectively). The spatial resolution of the global approach is twice the element size (16 and 32 voxels, i.e. 0.32 and $0.64 \mathrm{~mm}$, respectively). Sub-volumes of size 32 voxels (resp. 64 voxels) for the local approach were compared with elements of size 16 voxels (resp. 32 voxels) for the global approach. 


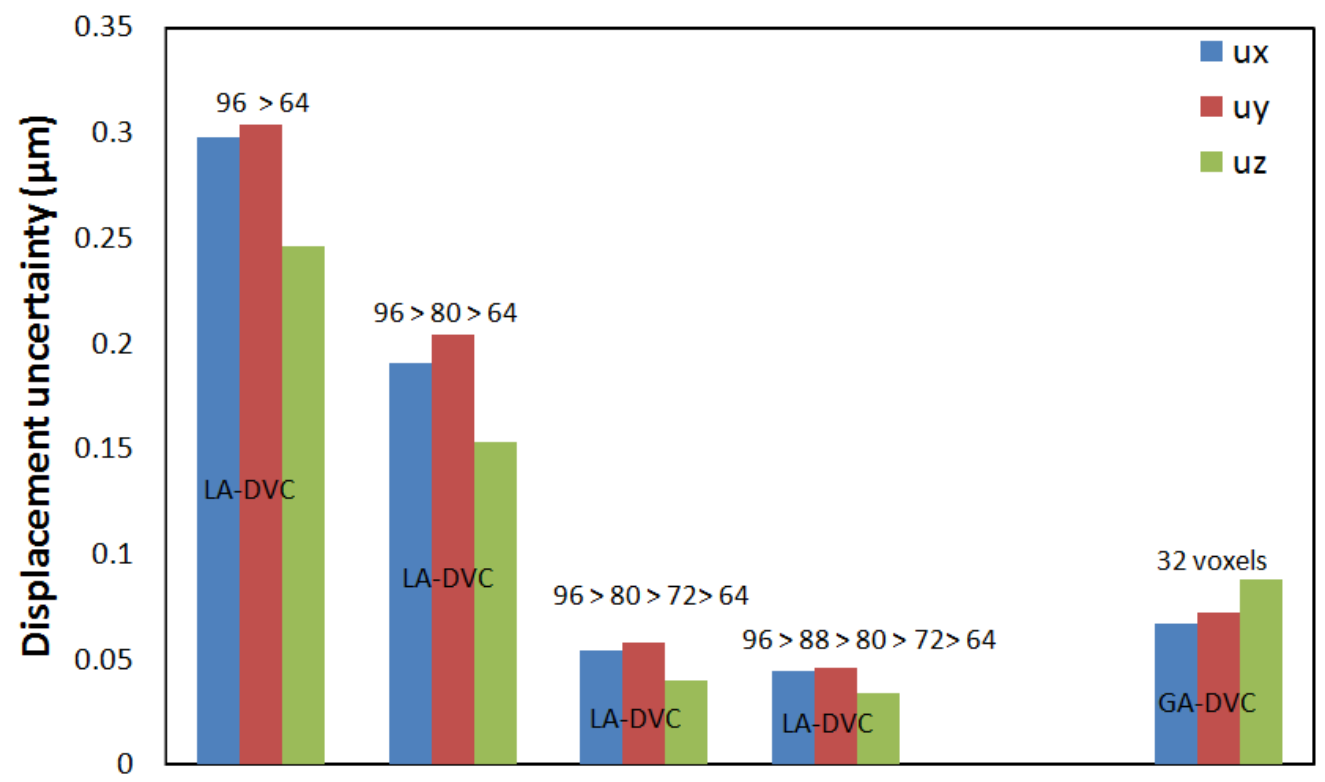

(a)

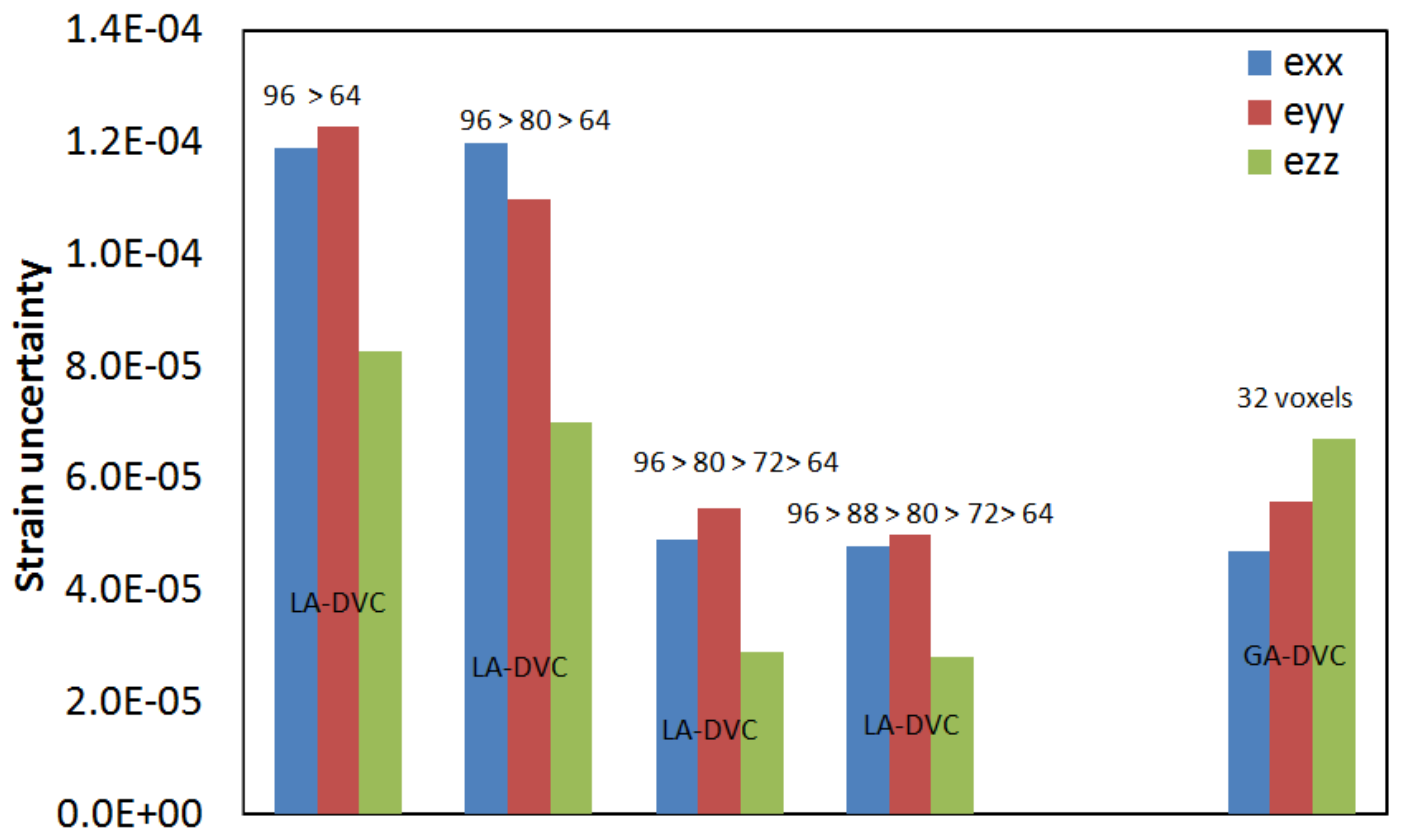

(b)

Fig. 7. The effect of increasing the number of intermediary sub-volumes during the multi-pass approach (LA-DVC) on the displacement uncertainty, $\sigma_{u}$, (a), and the strain uncertainty, $\sigma_{\varepsilon}$, (b). A prescribed displacement of 0.5 voxel was applied. Notations $x_{1}>x_{2} \ldots>x_{n}$ refer to successive passes using sub-volumes of $x_{1} \times x_{1} \times x_{1}$ voxels ${ }^{3}, x_{2} \times x_{2} \times x_{2}$ voxels ${ }^{3}$....to reach the final sub-volumes of $x_{n} \times$ $x_{n} \times x_{n}$ voxels $s^{3}$. Results are compared with those obtained with the global approach, using an element size of 32 voxels. 


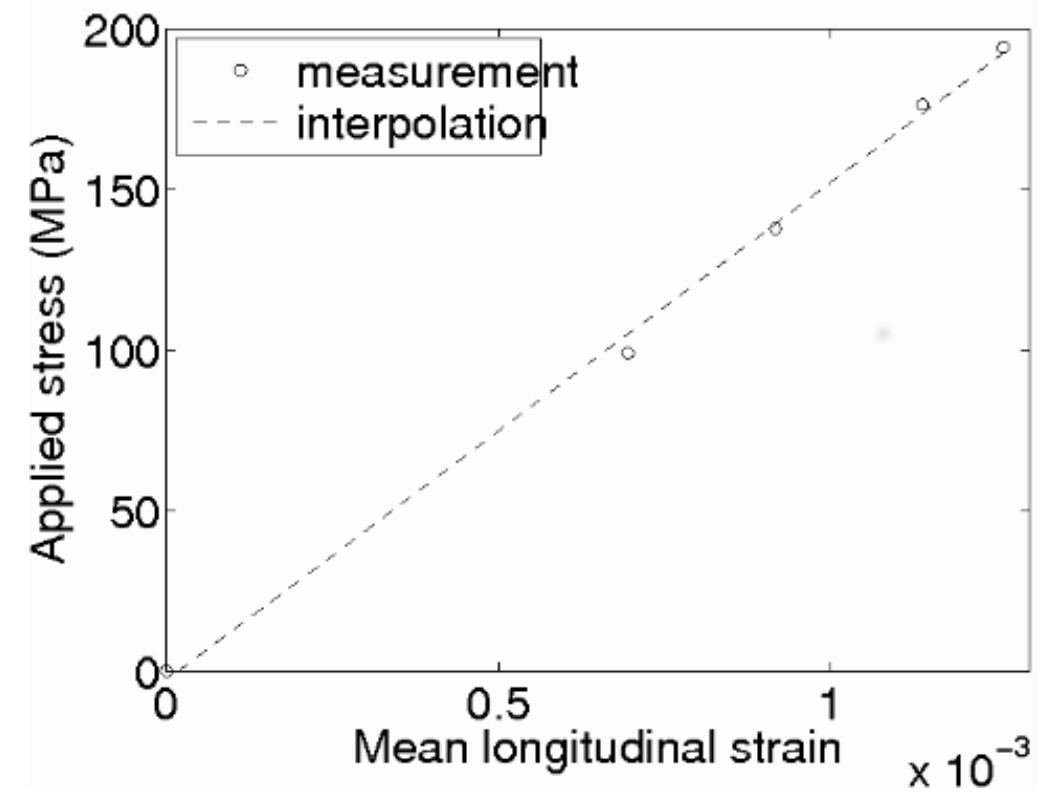

(a)

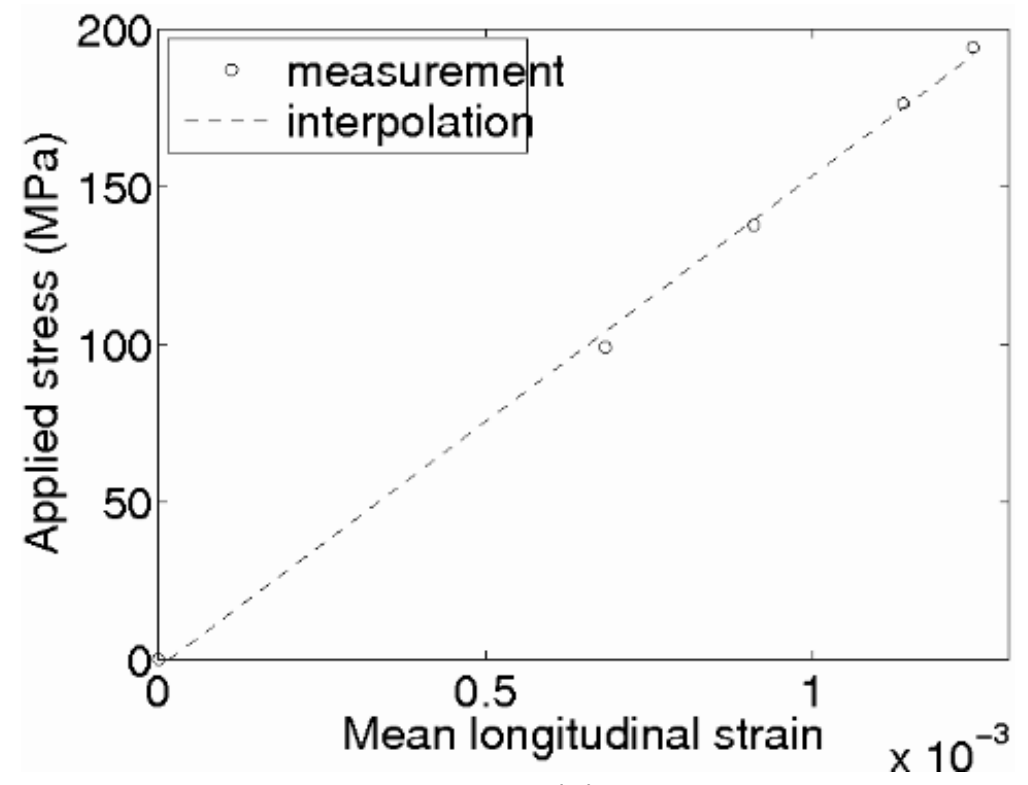

(b)

Fig. 8. Stress-strain curve of a nodular graphite cast iron deduced from the DVC analysis of five micro-CT scans, for the two correlation methods: (a) LA-DVC (sub-volume size: 32 voxels), (b) GADVC (element size: 16 voxels). The spatial resolution of the global approach is twice the element size. 


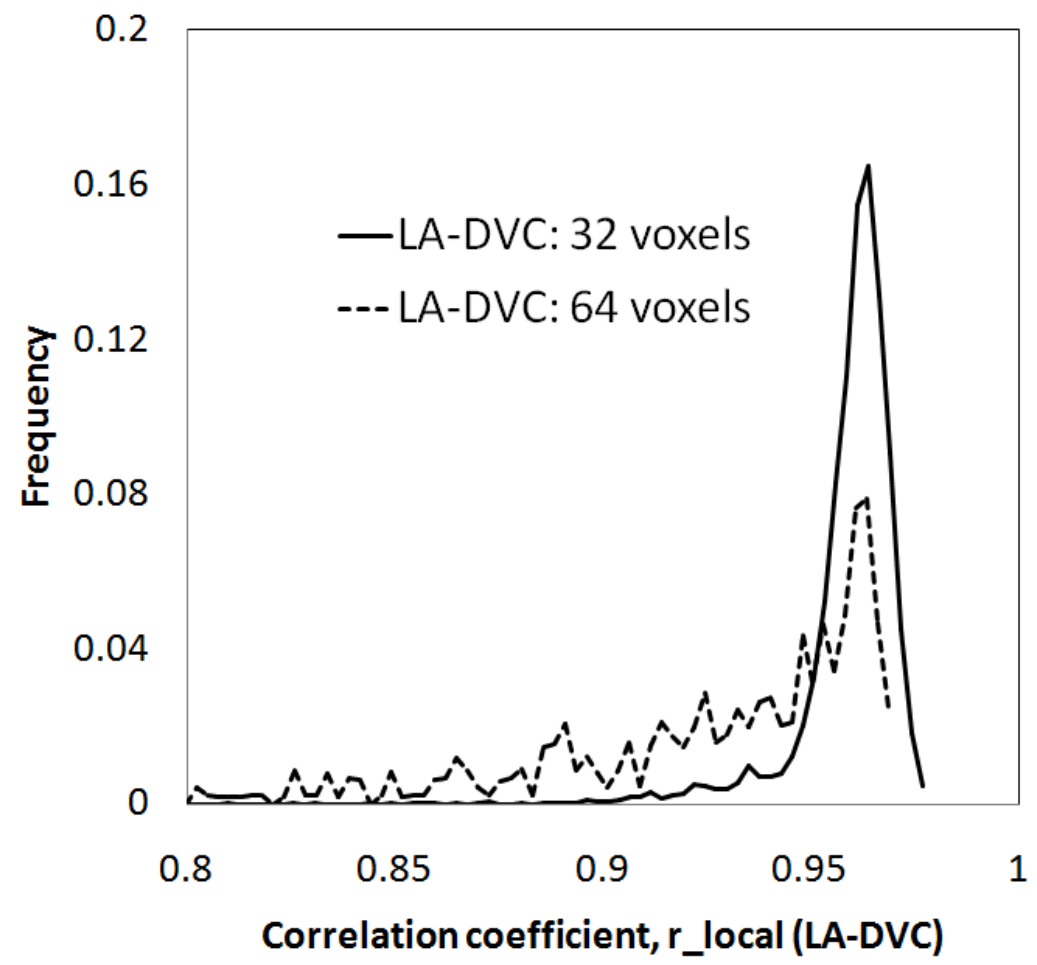

(a)

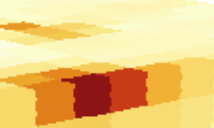
0.97

0.91 0.89

0.85

0.78

0.72
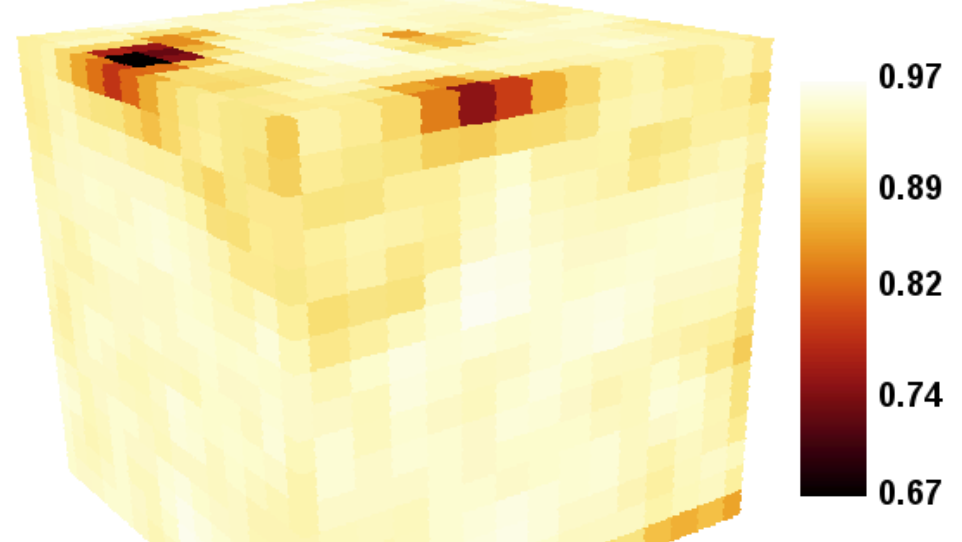

(b)

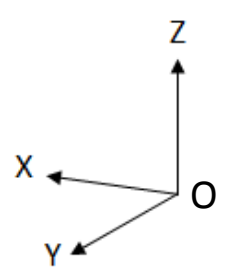

(c)

Fig. 9. (a) Histogram of the normalised cross-correlation coefficient, $r_{L A-D V C}$, over the VOI (Fig. 4); 3D visualisation of the correlation coefficient, $r_{L A-D V C}$, obtained with a sub-volume size of 32 voxels with $50 \%$ overlap, (b) and 64 voxels with $50 \%$ overlap, (c). 


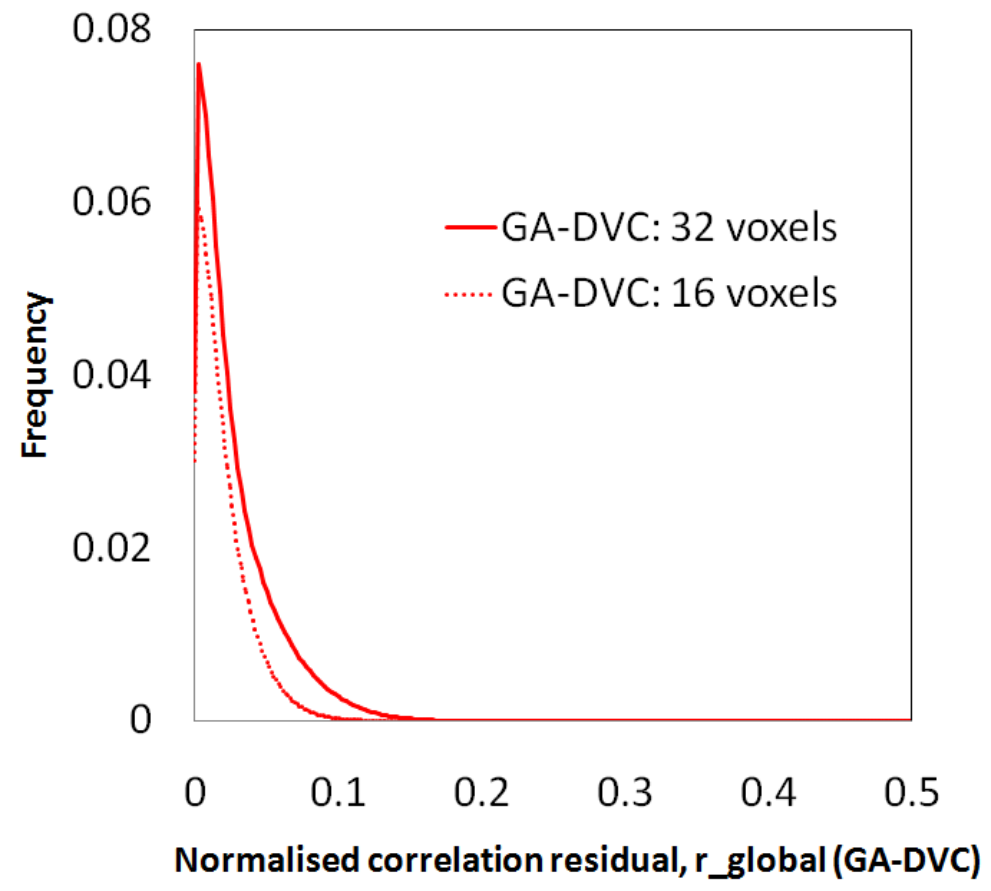

(a)

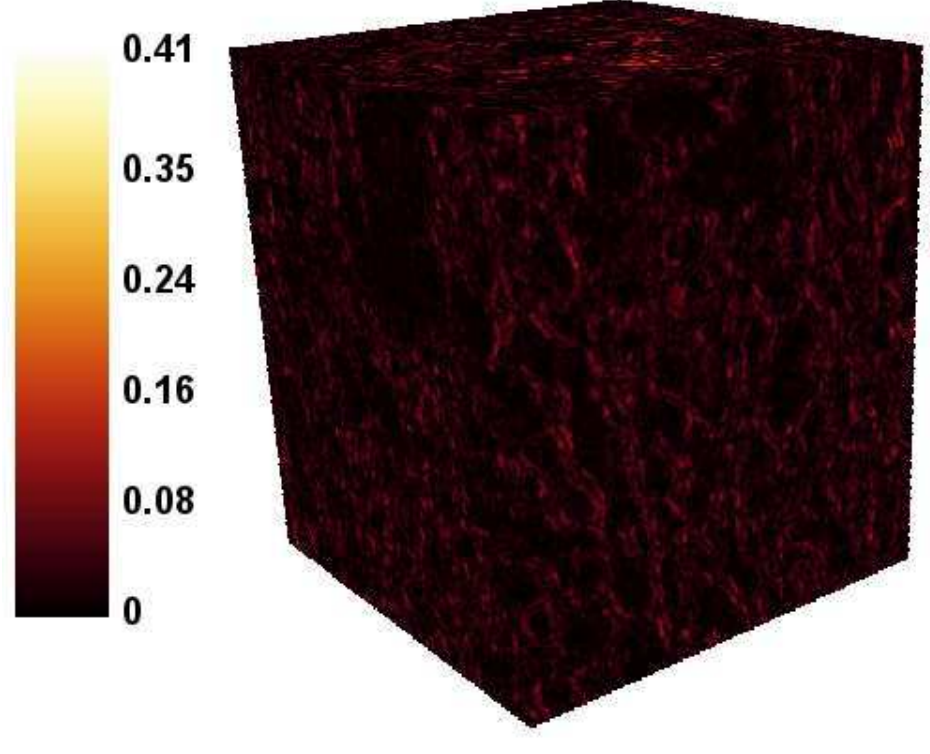

(b)

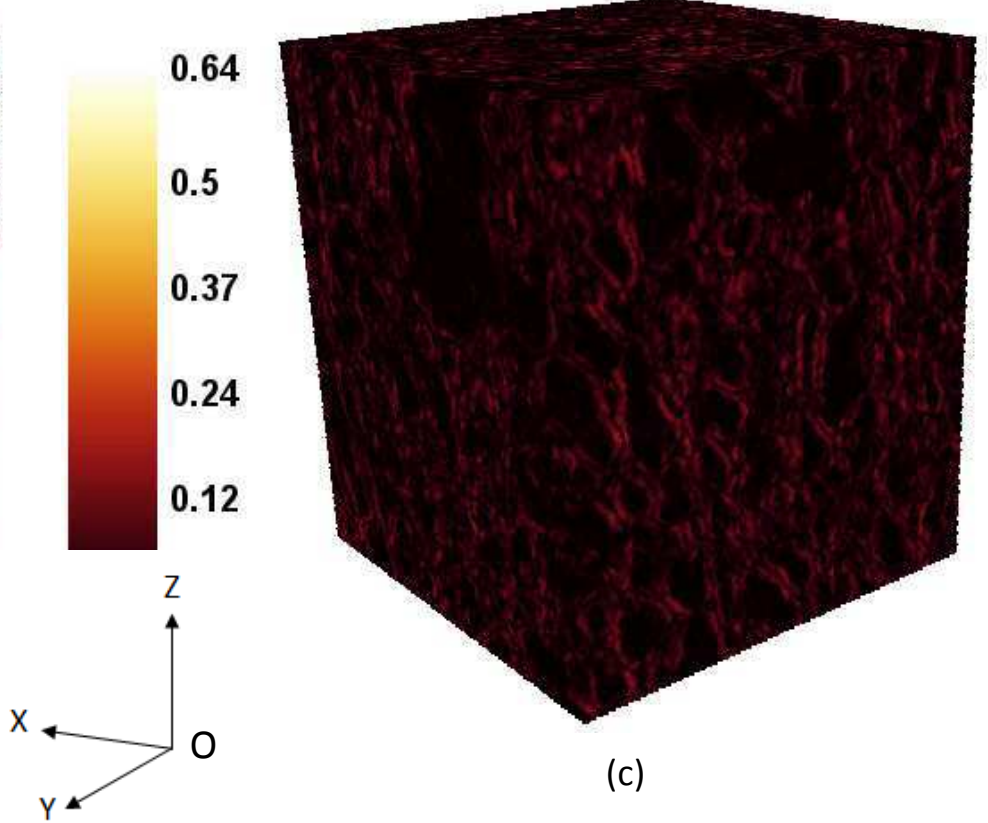

Fig. 10. (a) Histogram of the correlation residual, $r_{G A-D V C}$, over the VOI (Fig. 4); 3D visualisation of the correlation residual, $r_{L A-D V C}$, obtained with an element size of 16 voxels, (b) and 32 voxels, (c). 


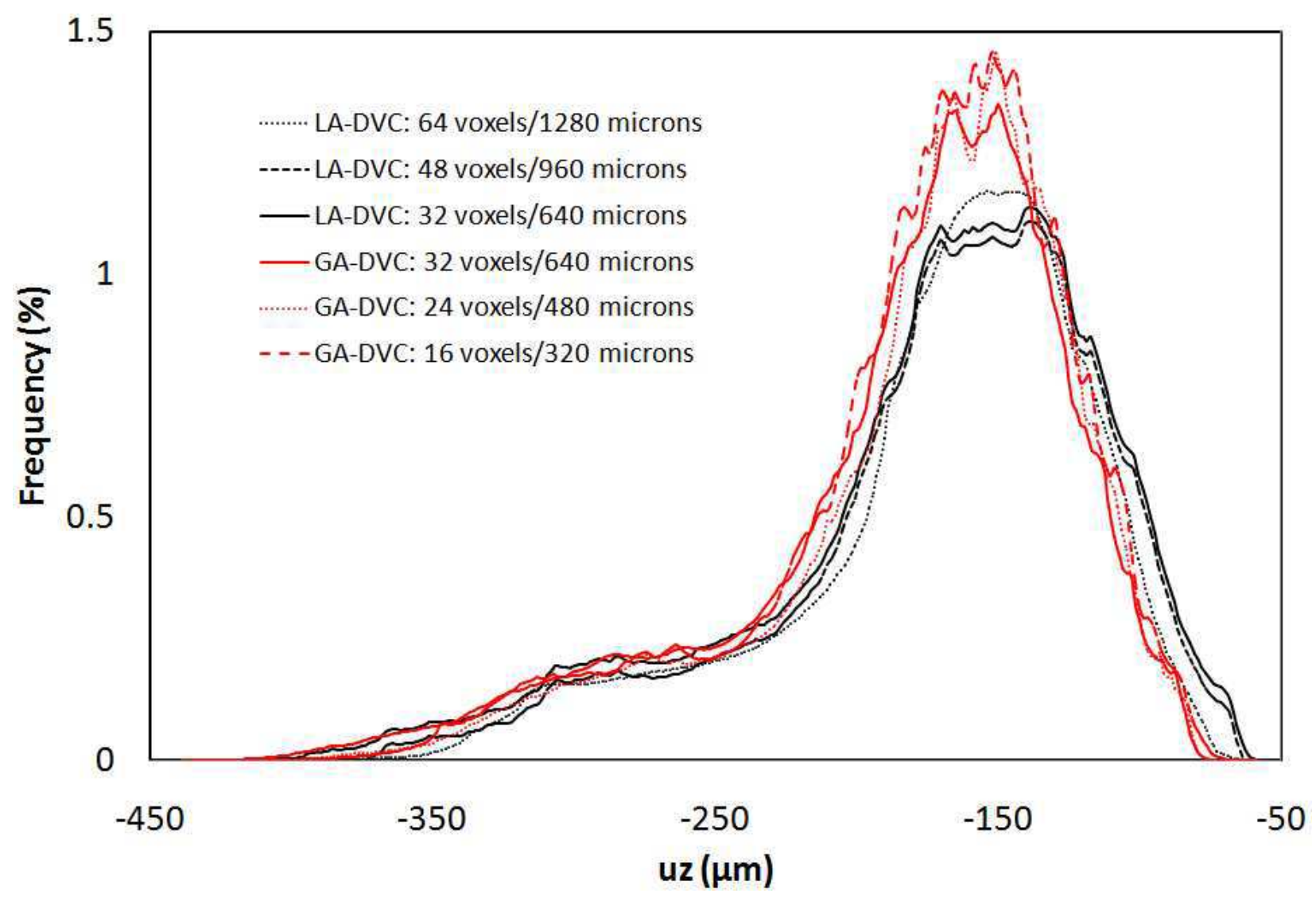

Fig. 11. The effect of the sub-volume or element size on the vertical displacement distribution $\left(u_{z}\right)$ for the two correlation techniques. The distributions were obtained from the displacements computed over the entire cylindrical specimen (diameter of $8.57 \mathrm{~mm}$ and height of $14.7 \mathrm{~mm}$ ). Note that the volume of interest (Fig. 4) was cropped at a distance of $\sim 1 \mathrm{~mm}$ from the top (maximum vertical displacement $\sim-254 \mu \mathrm{m}$, as illustrated in Fig 12c). The spatial resolution of the global approach is twice the element size. 


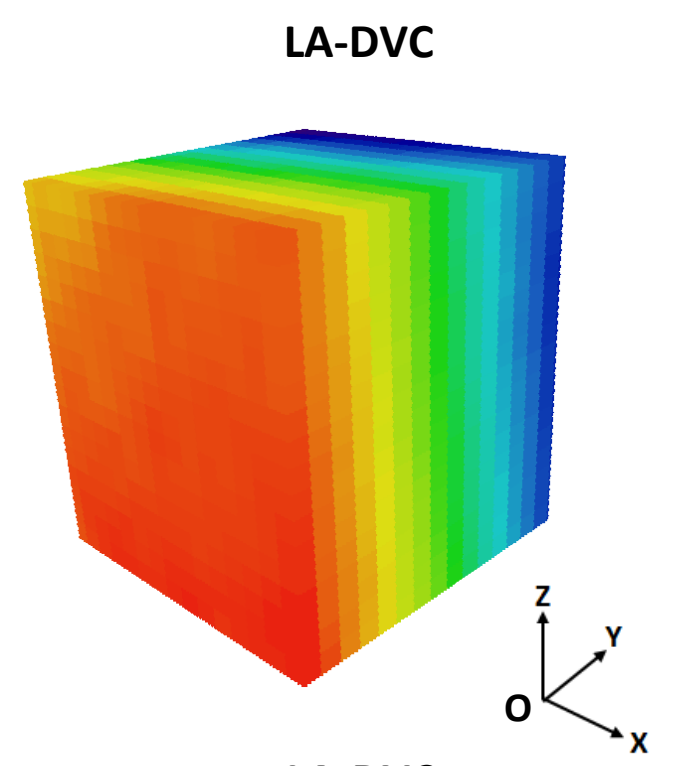

\section{$u_{x}(\mu \mathrm{m})$}
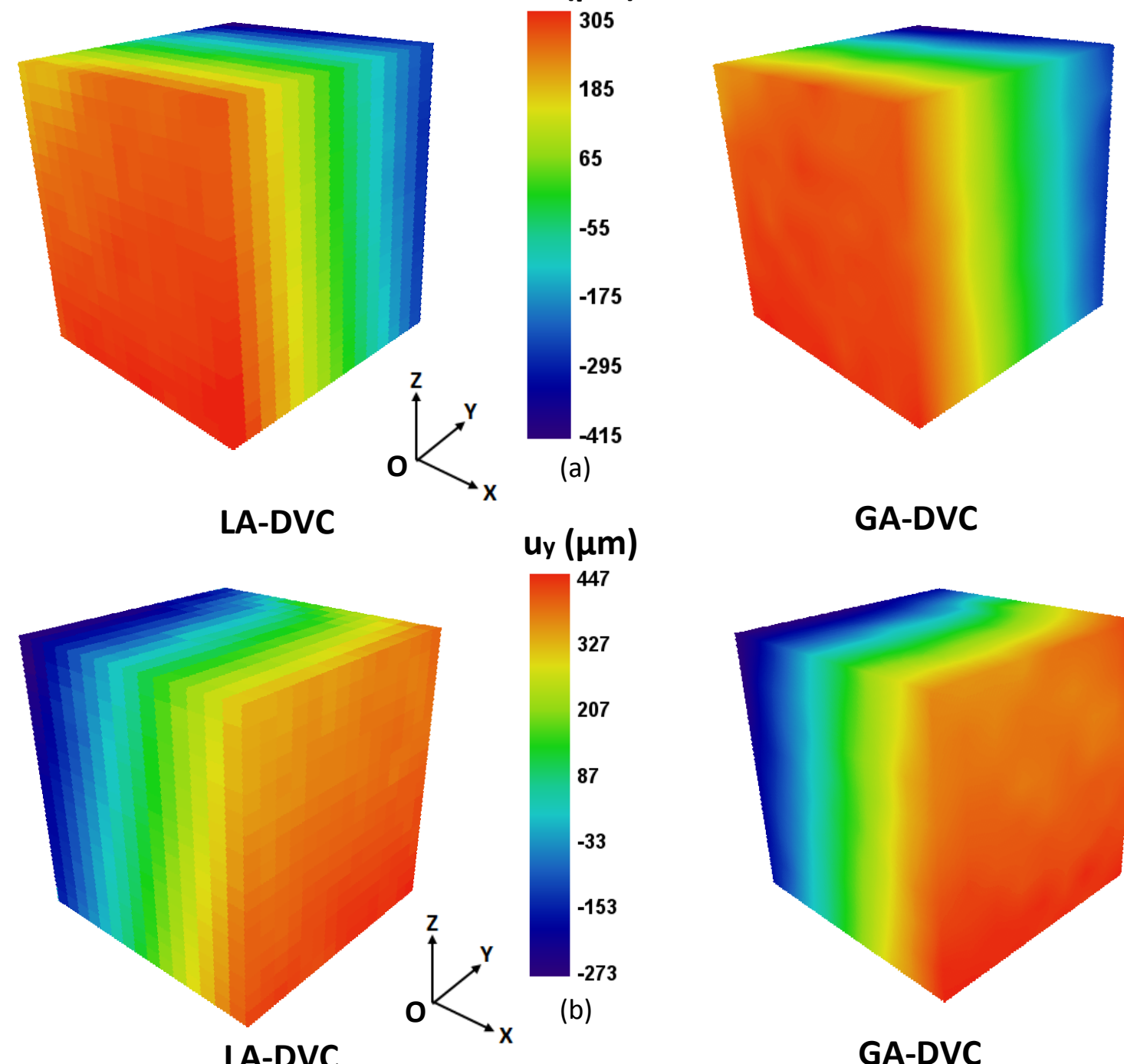

(a)

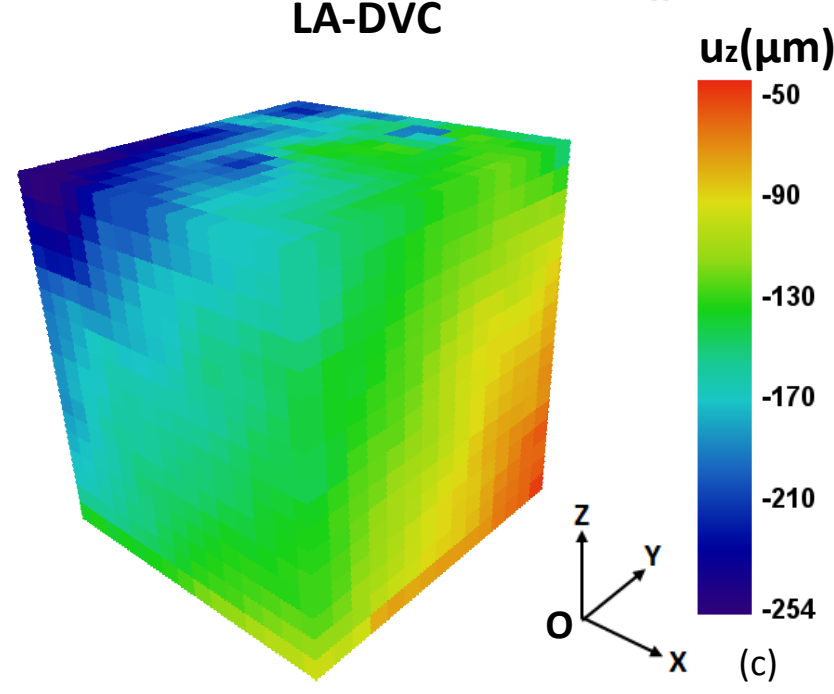

Uy $(\mu \mathrm{m})$

GA-DVC

447

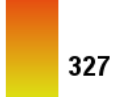

207

87

$-33$

$-153$

$-273$

(b)

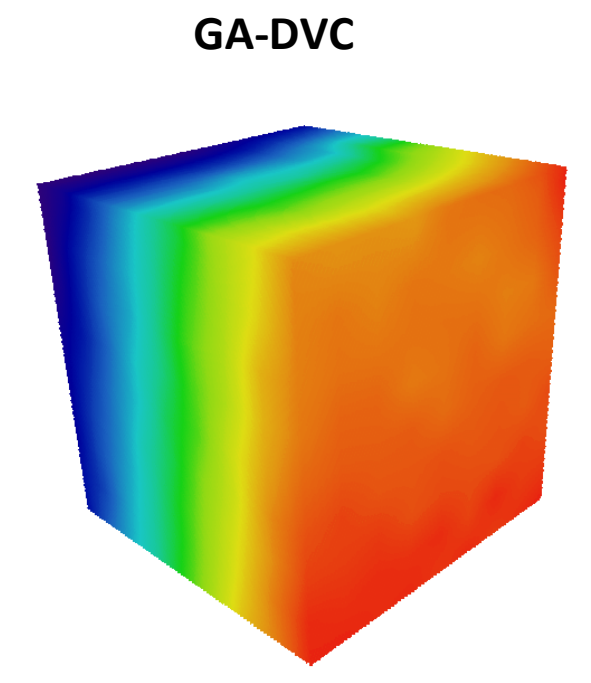

GA-DVC

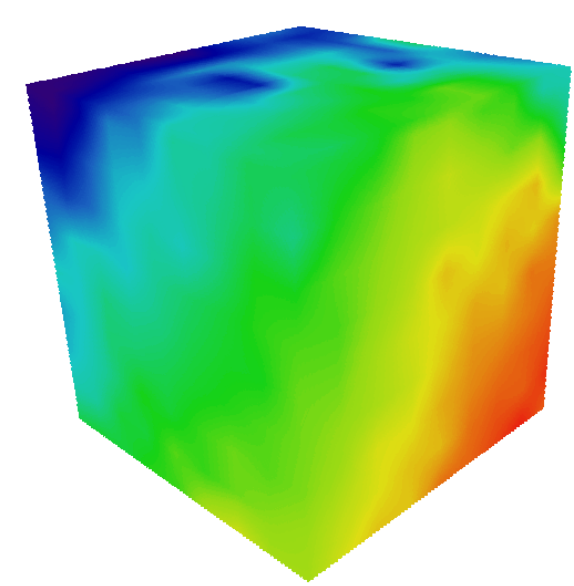

Fig. 12. 3D visualisation of the measured lateral and vertical displacements, $u_{x}, u_{y}$ and $u_{z}$ of the VOI (Fig. 4), for the two correlation methods (sub-volume size: $0.64 \mathrm{~mm}$ with $50 \%$ overlap; element size: $0.64 \mathrm{~mm}$ ): (a) $u_{x},(b) u_{y}$, (c) $u_{z}$. The macroscopic strain was applied along $(\mathrm{Oz})$ direction. 


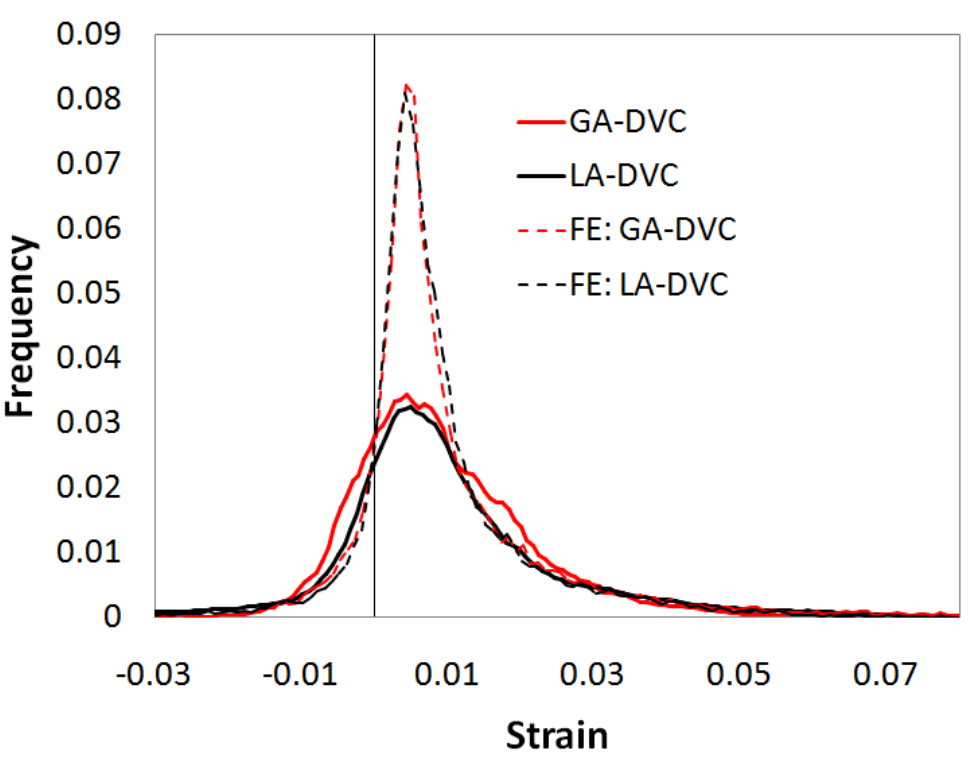

(a)

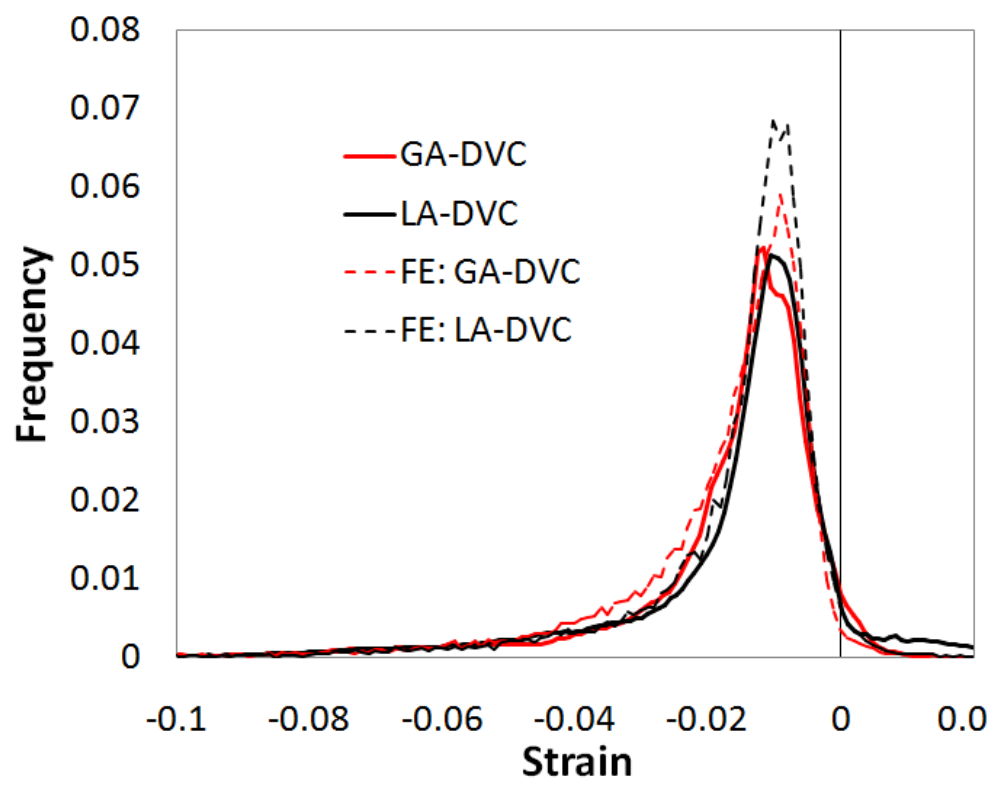

(c)

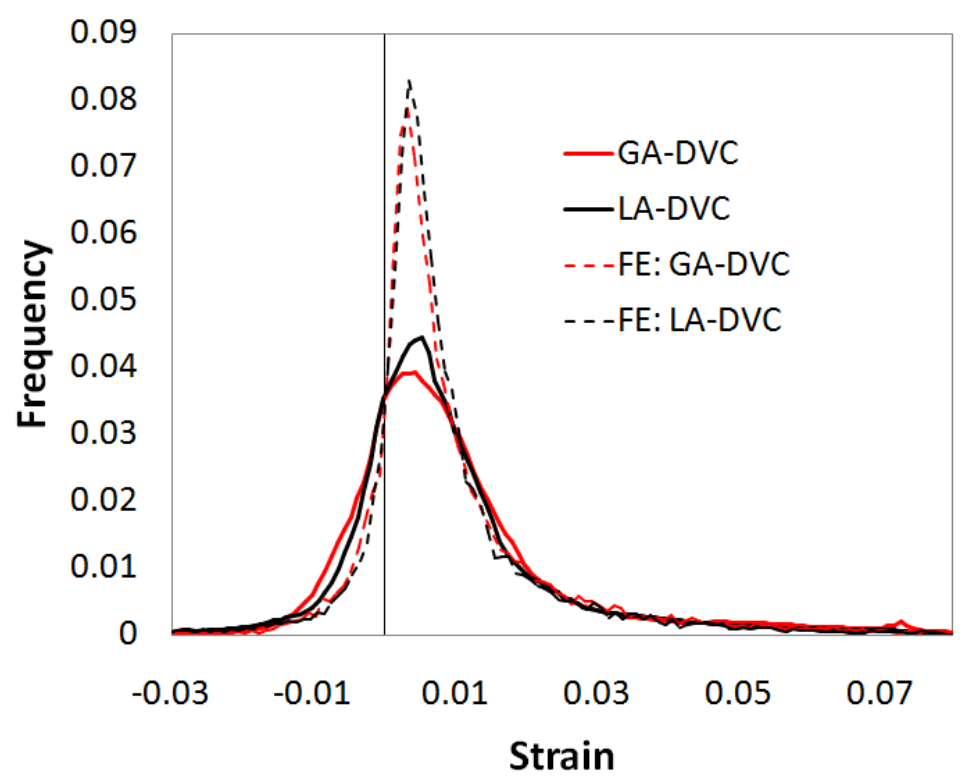

(b)

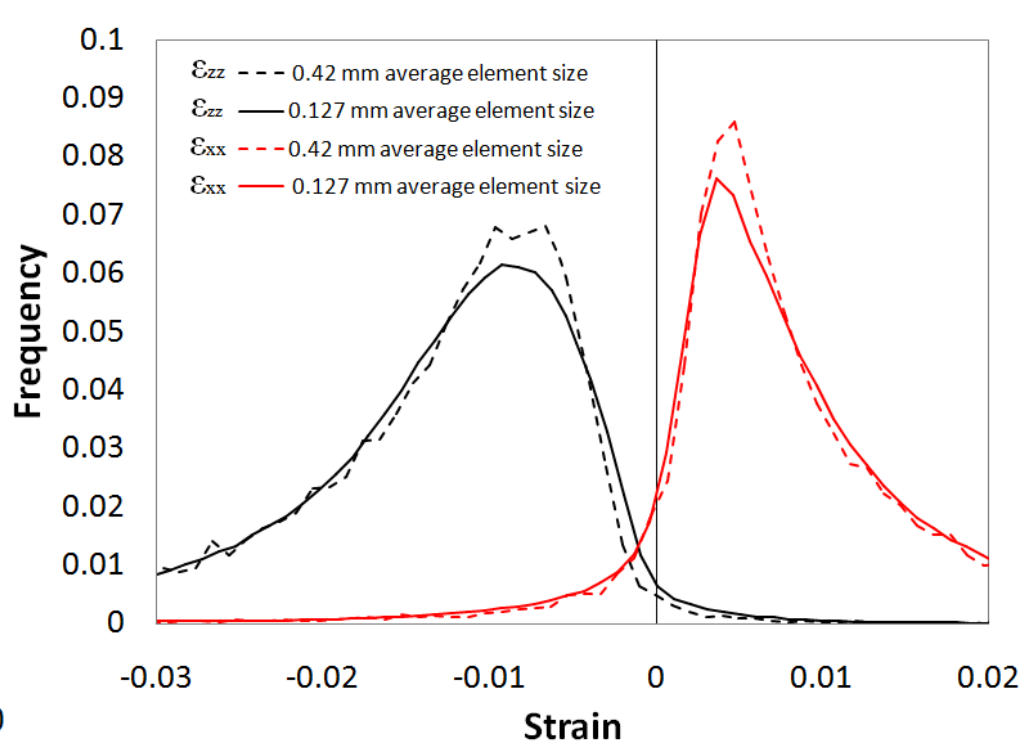

(d)

Fig. 13. Distributions of the vertical and the lateral strains over the VOI shown in Fig. 4: (a) $\varepsilon_{x x}$, (b) $\varepsilon_{y y}$, (c) $\varepsilon_{z z}$ and (d) the effect of mesh size on the distribution (FE: LA-DVC). The histograms were obtained with a class interval size of $\Delta \varepsilon=0.001$. The macroscopic strain was applied along $(\mathrm{Oz})$ direction. The experimental displacements obtained by LA-DVC and GA-DVC (sub-volume size: 0.64 $\mathrm{mm}$ with $50 \%$ overlap; element size: $0.64 \mathrm{~mm}$ ) were separately applied as boundary conditions at the mesh faces of the FE model (average mesh size: $0.42 \mathrm{~mm}$ ). 

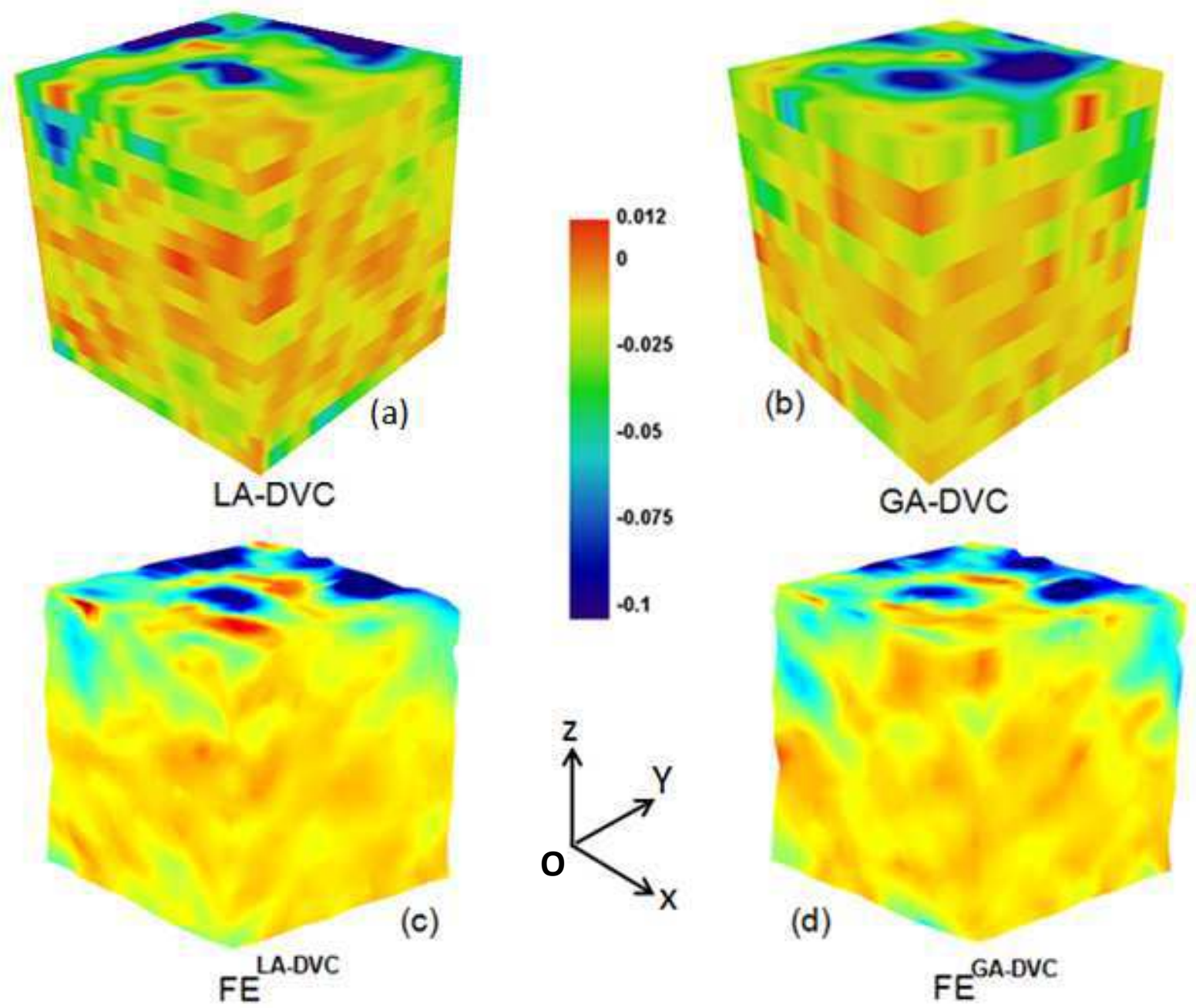

$\mathrm{FE}^{\mathrm{GA}-\mathrm{DVC}}$

Fig.14. 3D visualization of the vertical strain, $\varepsilon_{z z}$, of the VOI (Fig. 4): (a) LA-DVC (sub-volume size: $0.64 \mathrm{~mm}$ with $50 \%$ overlap), (b) GA-DVC (element size: $0.64 \mathrm{~mm}$ ), (c) FE model with boundary conditions applied from LA-DVC (average mesh size: $0.42 \mathrm{~mm}$ ), (d) FE model with boundary conditions applied from GA-DVC (average mesh size: $0.42 \mathrm{~mm}$ ). The macroscopic strain was applied along $(\mathrm{Oz})$ direction. 


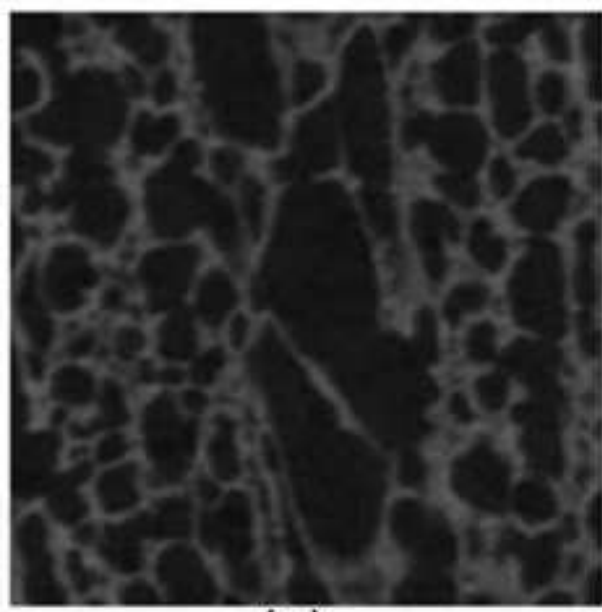

(a)

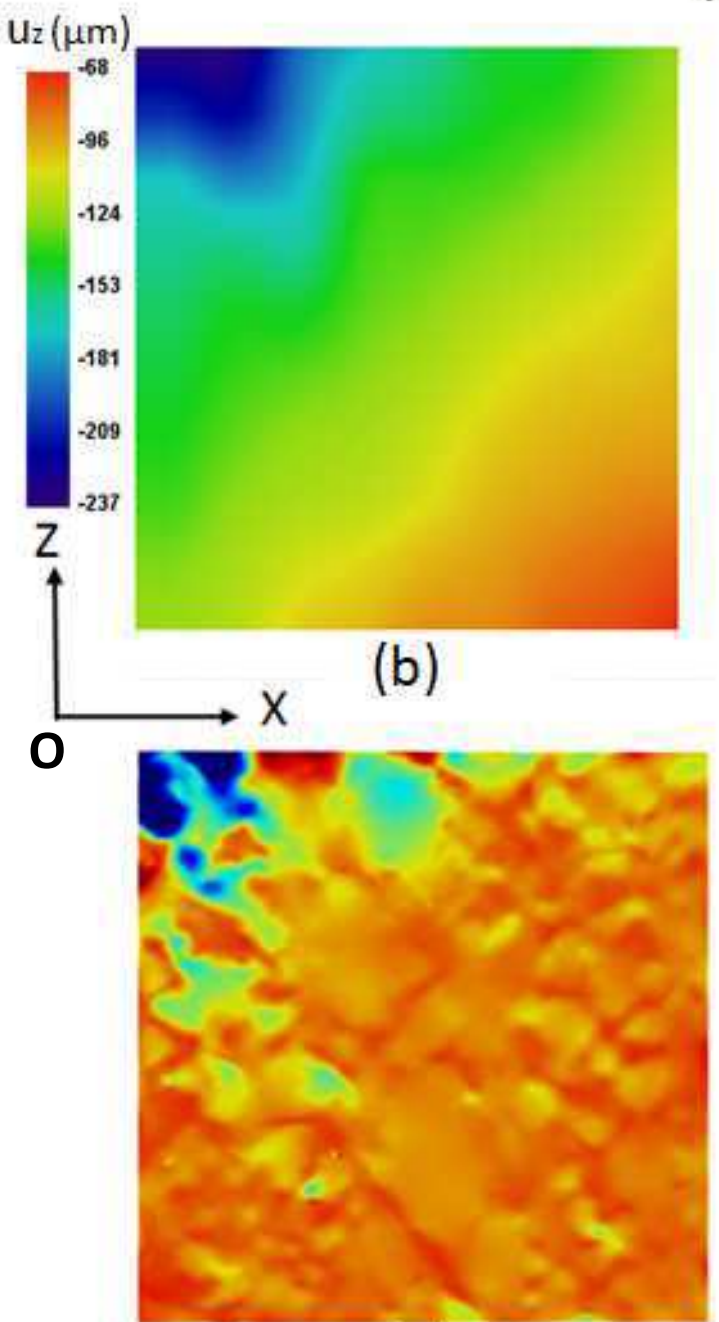

(d)

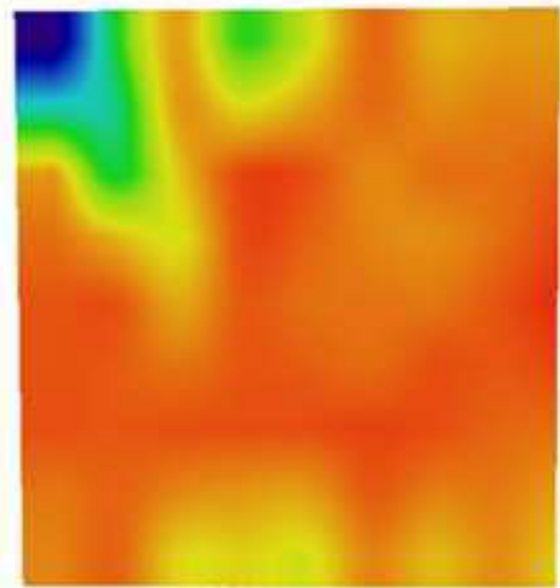

(c)

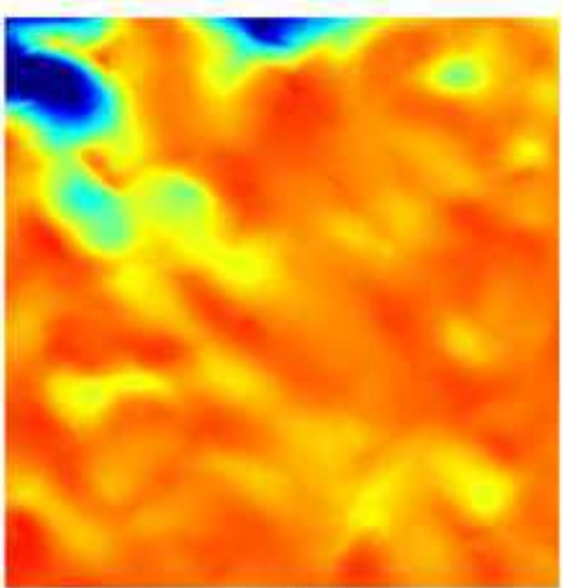

(e)

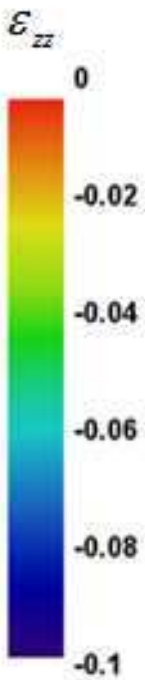

Fig. 15. Comparison of vertical strain magnitude, $\varepsilon_{z z}$, from DVC and FE model in a 2D section extracted from the core of the VOI (Fig. 4): (a): The micro-CT image, (b) $\mathrm{u}_{\mathrm{z}}$ : DVC (sub-volume size: $0.64 \mathrm{~mm}$ ), (c) $\varepsilon_{z z}$ : DVC (sub-volume size: $0.64 \mathrm{~mm}$ ), (d) $\varepsilon_{z z}$ :FE model (average mesh size: $0.127 \mathrm{~mm}$ ),

(e) $\varepsilon_{z z}: F E$ model (average mesh size: $0.42 \mathrm{~mm}$ ). The macroscopic strain was applied along (Oz) direction. Similar maps were obtained for LA-DVC and GA-DVC and, for the sake of clarity, only LADVC is represented. The DVC maps were obtained with $50 \%$ overlap and a bicubic interpolation. 


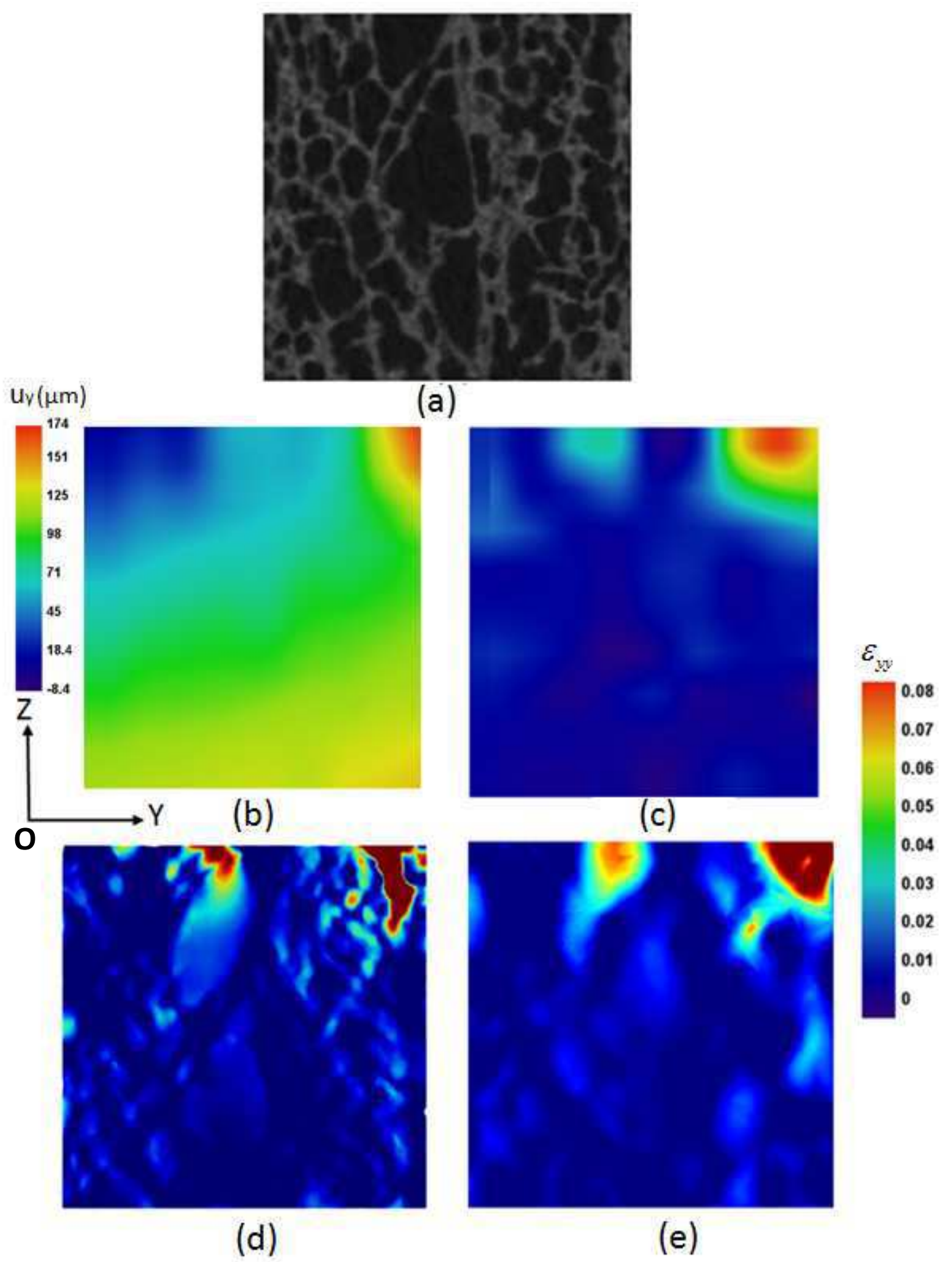

Fig. 16. Comparison of lateral strain magnitude, $\varepsilon_{y y}$, from the DVC and the FE model in a 2D section extracted from the core of the VOI (Fig. 4): (a) The micro-CT image; (b) $\mathrm{u}_{\mathrm{y}}$ : DVC (sub-volume size: 0.64 $\mathrm{mm}$ ), (c) $\varepsilon_{y y}$ : DVC (sub-volume size: $0.64 \mathrm{~mm}$ ), (d) $\varepsilon_{y y}:$ FE model (average mesh size: $0.127 \mathrm{~mm}$ ),

(e) $\varepsilon_{y y}$ : FE model (average mesh size: $0.42 \mathrm{~mm}$ ). The macroscopic strain was applied along (Oz) direction. Similar maps were obtained for LA-DVC and GA-DVC and, for the sake of clarity, only LADVC is represented. The DVC maps were obtained with $50 \%$ overlap and a bicubic interpolation. 


\begin{tabular}{|c|c|c|c|c|}
\hline \multirow{2}{*}{$\begin{array}{l}\text { Prescribed } \\
\text { displacement } \\
(\text { voxel } / \mu \mathrm{m})\end{array}$} & \multirow[t]{2}{*}{ DVC method } & \multicolumn{3}{|c|}{ Spatial average displacement (voxel $/ \mu \mathrm{m})$} \\
\hline & & $<u_{x}>$ & $<u_{y}>$ & $<u_{z}>$ \\
\hline \multirow[t]{4}{*}{$0.25 / 5$} & $\begin{array}{c}\text { GA-DVC } \\
\text { (32 voxels) }\end{array}$ & $0.2499 / 4.998$ & $0.2499 / 4.998$ & $0.2499 / 4.998$ \\
\hline & $\begin{array}{c}\text { GA-DVC } \\
\text { (16 voxels) }\end{array}$ & $0.2499 / 4.998$ & $0.2499 / 4.998$ & $0.2498 / 4.996$ \\
\hline & $\begin{array}{c}\text { LA-DVC } \\
\text { (32 voxels) }\end{array}$ & $0.2449 / 4.898$ & $0.2456 / 4.912$ & $0.2447 / 4.894$ \\
\hline & $\begin{array}{c}\text { LA-DVC } \\
\text { (64 voxels) }\end{array}$ & $0.2376 / 4.752$ & $0.2346 / 4.692$ & $0.2336 / 4.672$ \\
\hline \multirow[t]{4}{*}{$0.5 / 10$} & $\begin{array}{c}\text { GA-DVC } \\
\text { (32 voxels) }\end{array}$ & $0.5000 / 10$ & $0.5000 / 10$ & $0.5000 / 10$ \\
\hline & $\begin{array}{c}\text { GA-DVC } \\
\text { (16 voxels) }\end{array}$ & $0.5001 / 10.002$ & $0.5001 / 10.002$ & $0.5001 / 10.002$ \\
\hline & $\begin{array}{c}\text { LA-DVC } \\
\text { (32 voxels) }\end{array}$ & $0.4907 / 9.814$ & $0.4949 / 9.898$ & $0.4903 / 9.806$ \\
\hline & $\begin{array}{c}\text { LA-DVC } \\
\text { (64 voxels) }\end{array}$ & $0.4841 / 9.682$ & $0.4848 / 9.696$ & $0.4797 / 9.594$ \\
\hline \multirow[t]{4}{*}{$0.75 / 15$} & $\begin{array}{c}\text { GA-DVC } \\
\text { (32 voxels) }\end{array}$ & $0.7500 / 15$ & $0.7500 / 15$ & $0.7500 / 15$ \\
\hline & $\begin{array}{c}\text { GA-DVC } \\
\text { (16 voxels) }\end{array}$ & $0.7502 / 15.004$ & $0.7502 / 15.004$ & $0.7502 / 15.004$ \\
\hline & $\begin{array}{c}\text { LA-DVC } \\
\text { (32 voxels) }\end{array}$ & $0.7418 / 14.836$ & $0.7382 / 14.764$ & $0.7370 / 14.74$ \\
\hline & $\begin{array}{c}\text { LA-DVC } \\
\text { (64 voxels) }\end{array}$ & $0.7418 / 14.836$ & $0.7419 / 14.838$ & $0.7370 / 14.74$ \\
\hline
\end{tabular}

GA-DVC: Global approach to DVC; LA-DVC: Local approach to DVC

Table 1. Average displacements over the domain as functions of the prescribed value (correlation window: 32 and 64 voxels, i.e. 0.64 and $1.28 \mathrm{~mm}$ respectively). The spatial resolution of the global approach is twice the element size. Consequently, additional results with element sizes of $16 \times 16 \times 16$ voxels $^{3}\left(320 \times 320 \times 320 \mu \mathrm{m}^{3}\right)$ are also analysed. 


\begin{tabular}{|c|c|c|}
\hline Method & $\begin{array}{l}\text { Mean } \\
(\mu)\end{array}$ & $\begin{array}{l}\text { Standard deviation } \\
\qquad\left(\sigma_{\mu}\right)\end{array}$ \\
\hline $\begin{array}{c}\text { LA-DVC } \\
\text { sub-volume size: } 0.64 \mathrm{~mm} \\
\text { (32 voxels) } \\
\text { sub-volume size: } 1.28 \mathrm{~mm} \\
\text { (64 voxels) }\end{array}$ & 0.96 & 0.015 \\
\hline $\begin{array}{c}\text { GA-DVC } \\
\text { element size: } 0.32 \mathrm{~mm} \\
\text { (16 voxels) } \\
\text { element size: } 0.64 \mathrm{~mm} \\
\text { (32 voxels) }\end{array}$ & 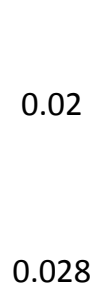 & 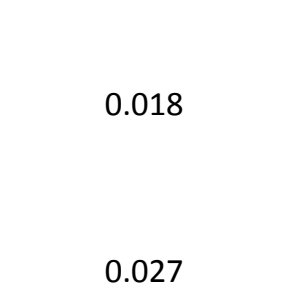 \\
\hline
\end{tabular}

Table 2. Mean, $\mu$ and standard deviation, $\sigma_{\mu}$, of the correlation coefficient, $r_{L A-D V C}$, and correlation residual, $r_{G A-D V C}$, obtained on the considered VOI (Fig. 4) using both DVC methods (see Figs. 9a and 10a). 


\begin{tabular}{|c|c|c|c|c|}
\hline Method & $\begin{array}{c}\text { Mean }(\mu) \text { and } \\
\text { Standard } \\
\text { deviation }\left(\sigma_{\mu}\right)\end{array}$ & $\varepsilon_{x x}$ & $\varepsilon_{y y}$ & $\varepsilon_{z z}$ \\
\hline $\begin{array}{c}\text { LA-DVC } \\
\text { (sub-volume size: } 0.64 \mathrm{~mm} \text { ) }\end{array}$ & $\begin{array}{l}\mu^{L A-D V C} \\
\sigma_{\mu}^{L A-D V C}\end{array}$ & $\begin{array}{l}0.0094 \\
0.0130\end{array}$ & $\begin{array}{l}0.0097 \\
0.0168\end{array}$ & $\begin{array}{l}-0.0176 \\
0.0282\end{array}$ \\
\hline $\begin{array}{c}\mathrm{FE}_{\mathrm{LA}-\mathrm{Dvc}} \text { model } \\
\text { (mesh size: } 0.127 \mathrm{~mm} \text { ) }\end{array}$ & $\begin{array}{l}\mu^{F E-L A} \\
\sigma_{\mu}^{F E-L A}\end{array}$ & $\begin{array}{l}0.0091 \\
0.0155\end{array}$ & $\begin{array}{l}0.0096 \\
0.0194\end{array}$ & $\begin{array}{l}-0.0171 \\
0.0187\end{array}$ \\
\hline $\begin{array}{c}\mathrm{FE}_{\mathrm{LA}-\mathrm{DV} c} \text { model } \\
\text { (mesh size: } 0.42 \mathrm{~mm} \text { ) }\end{array}$ & $\begin{array}{c}\mu^{F E-L A} \\
\sigma_{\mu}^{F E-L A}\end{array}$ & $\begin{array}{l}0.0092 \\
0.0144\end{array}$ & $\begin{array}{l}0.0097 \\
0.0170\end{array}$ & $\begin{array}{l}-0.0172 \\
0.0184\end{array}$ \\
\hline $\begin{array}{c}\text { GA-DVC } \\
\text { (element size: } 0.64 \mathrm{~mm} \text { ) }\end{array}$ & $\begin{array}{l}\mu^{G A-D V C} \\
\sigma_{\mu}{ }^{G A-D V C}\end{array}$ & $\begin{array}{l}0.0095 \\
0.0124\end{array}$ & $\begin{array}{l}0.0105 \\
0.0171\end{array}$ & $\begin{array}{l}-0.0172 \\
0.0165\end{array}$ \\
\hline $\begin{array}{c}\mathrm{FE}_{\mathrm{GA}-\mathrm{Dvc}} \text { model } \\
\text { (mesh size: } 0.127 \mathrm{~mm} \text { ) }\end{array}$ & $\begin{array}{c}\mu^{F E-G A} \\
\sigma_{\mu}^{F E-G A}\end{array}$ & $\begin{array}{l}0.0095 \\
0.0195\end{array}$ & $\begin{array}{l}0.0106 \\
0.0207\end{array}$ & $\begin{array}{l}-0.0176 \\
0.0197\end{array}$ \\
\hline $\begin{array}{c}\mathrm{FE}_{\mathrm{GA}-\mathrm{DV} c} \text { model } \\
\text { (mesh size: } 0.42 \mathrm{~mm} \text { ) }\end{array}$ & $\begin{array}{c}\mu^{F E-G A} \\
{\sigma_{\mu}}^{F E-G A}\end{array}$ & $\begin{array}{l}0.0094 \\
0.0177\end{array}$ & $\begin{array}{l}0.0105 \\
0.0176\end{array}$ & $\begin{array}{l}-0.0173 \\
0.0192\end{array}$ \\
\hline
\end{tabular}

Table 3. Mean, $\mu$ and standard deviation, $\sigma_{\mu}$, of the axial and lateral strain distributions obtained using the FE model and both DVC methods (see Fig. 13). $\mathrm{FE}_{\mathrm{LA}-\mathrm{DVC}}$ (resp. $\mathrm{FE}_{\mathrm{GA}-\mathrm{DVC}}$ ) refers to the FE model response calculated with experimental displacements obtained with the local (resp. global) approach, LA-DVC (resp. GA-DVC). 